\title{
Participação feminina na pesquisa sobre tecnologia da informação no Brasil: grupos de pesquisa $e$ produção científica de teses e dissertações*
}

\author{
Jussara Ribeiro de Oliveira** \\ Lívia Coelho Mello*** \\ Camila Carneiro Dias Rigolin****
}

\section{Resumo}

Este trabalho mapeou a natureza da participação feminina na pesquisa sobre tecnologia da infirmação (TI) no Brasil, sob duas perspectivas: a presença de mulheres nos grupos de pesquisa cadastrados e certificados no Diretório dos Grupos de Pesquisa do CNPq e na produção científica de teses e dissertações depositadas na Biblioteca Digital de Teses e Dissertações do IBICT. Os resultados retratam a configuração dos grupos de pesquisa e da produção científica de tese e dissertações no campo de TI, no Brasil, além de gerar indicadores que confirmam a concentração de mulheres em áreas de conhecimento ditas feminizadas, além de sugerirem a ocorrência de barreiras à sua ascensão hierárquica.

Palavras-chave: Tecnologia da Informação, Gênero, Mulheres, Grupos de Pesquisa, Teses e Dissertações.

* Recebido em 18 de janeiro de 2017, aceito em 15 de maio de 2018.

** Doutoranda do Programa de Pós-Graduação em Ciência, Tecnologia e Sociedade da Universidade Federal de São Carlos (PPGCTS-UFSCar), São Carlos, Brasil. darksaj@gmail.com / https://orcid.org/0000-0002-3583-3980

*** Doutora em Ciência, Tecnologia e Sociedade, Universidade Federal de São Carlos (UFSCAR), São Carlos, Brasil. liviacmelo@yahoo.com.br / https://orcid.org/0000-0002-5888-6866

**** Professora do Departamento de Ciência da Informação, do Programa de Ciência, Tecnologia e Sociedade (PPGCTS) e do Programa de Pós-Graduação em Gestão de Organizações e Sistemas Públicos (PPGGOSP) da Universidade Federal de São Carlos (UFSCAR), São Carlos, Brasil. diasrigolin@ufscar.br / https://orcid.org/0000-0002-9400-2837 
Female Participation in Information Technology Research in Brazil: Research Groups and Scientific Production of Theses and Dissertations

\begin{abstract}
This study mapped the nature of women's participation in research on information technology (IT) in Brazil considering the presence of women in research groups registered and certified in the Research Group Directory of CNPq and the production of theses and dissertations found in the Digital Library of Theses and Dissertations of IBICT. The results portray the configuration of research groups and the theses and dissertations about IT in Brazil, and provide indicators that confirm a concentration of women in fields of knowledge said to be feminized and suggest the occurrence of "glass-ceiling" barriers for women.
\end{abstract}

Keywords: Information Technology, Gender, Women, Research Groups, Thesis and Dissertations. 


\section{Introdução}

Este artigo analisa a participação feminina em grupos de pesquisa da área de Tecnologia da Informação (TI), no Brasil. Seu objetivo foi mapear, quantitativamente e qualitativamente, a presença de mulheres na pesquisa acadêmica sobre Tecnologia da Informação, no Brasil, caracterizando seu perfil, distribuição por áreas de conhecimento $e$ instituições $e$ sua inserção no sistema de recompensas da ciência. Neste sentido, procura responder a uma lacuna referente à limitação das estatísticas $e$ indicadores de pesquisa, ciência, tecnologia e inovação, com recorte de gênero. Foi feito um levantamento da presença de mulheres em grupos cadastrados, atualizados e certificados no Diretório dos Grupos de Pesquisa do Conselho Nacional de Desenvolvimento Científico e Tecnológico (DGP-CNPq), segundo dados do censo de 2014, associado a um estudo bibliométrico de teses e dissertações sobre Tecnologia da Informação, disponibilizadas na Biblioteca Digital Brasileira de Teses e Dissertações do Instituto Brasileiro de Informação em Ciência e Tecnologia (BDTD/IBICT).

As teorias feministas de gênero, trabalho, ciência $e$ tecnologia percorreram um longo caminho nas últimas quatro décadas. Do campo de estudos de gênero nas organizações emergiram contribuições teóricas e empíricas que tornaram o gênero visível nos estudos organizacionais, desmistificaram a suposta neutralidade de gênero no mundo do trabalho $e$ demonstraram como o gênero está profundamente inserido nas estruturas e culturas das organizações públicas e privadas (Calas, Smircich, Bourne, 2009). Mais de quarenta anos depois, esta corrente ainda questiona a persistente caracterização das mulheres como "o outro", em diferentes ambientes de trabalho e reivindica uma mudança de foco na avaliação das variadas expressões de feminização presentes nas organizações e como, quando e por quais razões estas são legitimadas ou estigmatizadas (Lewis, 2014).

Por sua vez, as discussões sobre o gênero e a forma como ele influencia o trabalho de pesquisa são discutidas há muito tempo na literatura que investiga as dimensões do gênero na 
produção do conhecimento, contribuindo para a desconstrução de estereótipos e representações que visam atribuir causas naturais às diferenças entre homens $e$ mulheres dentro das carreiras $e$ comunidades científicas. Referências epistemológicas desta corrente estão situadas pincipalmente no campo dos Estudos Sociais da Ciência e Tecnologia e podem ser encontradas nos estudos de Keller (1985); Harding (2008); Longino (1990); Haraway (1991); Schiebinger (2008), entre outros.

Em primeiro lugar, esses estudos buscaram analisar a história da participação feminina em instituições de pesquisa. Em segundo lugar, questionaram a forma como a própria ciência define a natureza das mulheres. Em terceiro lugar, dedicaram-se ao diagnóstico das distorções nas próprias normas e métodos da ciência e como essas distorções criam e reproduzem mecanismos de segregação nas carreiras científicas e tecnológicas.

Neste debate, cumpre mencionar as críticas e sugestões exteriorizadas pela abordagem standpoint theory e pelos estudos feministas pós-colonialistas, correntes que contribuíram para as discussões metodológicas e epistemológicas nos estudos de gênero, e para o ativismo político, ao defender três pontos de vista centrais: o conhecimento é socialmente situado; os grupos marginalizados são socialmente situados de uma forma que lhes confere repertório e ciência para apresentar questões que outros grupos não fariam; a pesquisa sobre relações de poder e gênero deve estar centrada nas vidas e experiências destes grupos (Wylie, 2017). Em especial, os estudos feministas pós-colonialistas apontaram o equívoco das generalizações universalistas sobre as mulheres como um grupo homogêneo, chamando a atenção para o gênero enquanto categoria fluida e para a interseccionalidade (Harding, 2009): a influência de condições e posições estruturais tais como classe, etnia, valores culturais e também identidade sexual.

As fertilizações cruzadas dos estudos feministas com os estudos sociais da tecnologia rejeitaram o estereótipo das mulheres como incompetentes ou invisíveis nos domínios da tecnologia, assumindo que esta última também é cultura, de modo 
que a associação automática de homens e máquinas é o resultado de uma construção histórica e cultural de gênero (Wajcman, 2010). Tais estudos reivindicaram a resignificação das tecnologias da vida cotidiana (Cowan, 1976) e colocaram sob escrutínio as concepções padronizadas de inovação e o papel oculto das mulheres na mudança tecnológica (Ranga; Etzkowitz, 2010). A inovação tem gênero, uma vez que é moldada pelas circunstâncias sociais em que ocorre, mas a mudança técnica também pode influenciar as relações de poder e de gênero: a relação entre gênero $e$ inovação não é determinista, mas fluida e situada.

Outros autores celebraram as tecnologias digitais como potencialmente transformadoras para as mulheres, enfatizando sua capacidade de agência. As análises feministas de tecnologia caminharam para além da abordagem das "mulheres e da tecnologia" para examinar os próprios processos através dos quais a tecnologia é desenvolvida e utilizada, bem como aquelas em que o gênero é constituído, questionando não apenas o monopólio masculino da tecnologia, mas também a forma como o gênero é incorporado na própria tecnologia. Talvez o otimismo desta literatura seja resumido por Haraway (1991). Provocativa, ela prefere ser um ciborgue - um híbrido de organismo e artefatos tecnológicos - e observa poder da ciência e da tecnologia para criar novos significados e entidades. A engenharia genética, a tecnologia reprodutiva $e$ o advento da realidade virtual são vistos como ideias desafiadoras, onde nem o gênero nem a tecnologia são considerados como pré-existentes, nem a relação entre eles é imutável.

Apesar dos avanços na discussão teórica, persiste a subrepresentação de mulheres nas áreas $\mathrm{STEM}^{1}$, demonstrada empiricamente em diferentes trabalhos que apontam o equívoco de creditá-la exclusivamente a "lacunas individuais", o que remete a interpretações limitadas do conceito de meritocracia e de uma academia governada exclusivamente por avaliações objetivas ou

1 Ciências, Tecnologia, Engenharia e Matemática ou Science, Technology, Engineering and Math, no acrônimo em inglês. 
um ethos da ciência (Merton, 1968). Há constrangimentos estruturais, culturais e políticos que definem o que é considerado meritório, desde crenças que norteiam o reconhecimento dos atributos de liderança, até normas que definem parâmetros de recrutamento e progressão (Nielsen, 2016).

Muitos estudos identificaram as barreiras estruturais à participação das mulheres relacionando a discriminação sexual no emprego $e$ ao tipo de socialização e educação que as meninas recebem (Harding, 2008). Os estereótipos sexuais nas escolas foram expostos, em particular os processos pelos quais meninas $e$ meninos são canalizados para diferentes disciplinas $e$ a ligação entre a educação e o mercado de trabalho. Estas pesquisas destacaram o caráter da feminilidade encorajada pela cultura e seu impacto na sub-representação das mulheres nas comunidades científicas.

Também os estudos bibliométricos contribuíram com pesquisas que demonstraram a desigualdade de gênero na produção e produtividade científica, no financiamento da pesquisa e no sistema de recompensas da ciência ao evidenciar discrepâncias de citação, premiação e reconhecimento entre os pares. Knobloch-Westerwick, Glynn e Huge (2013) demonstraram que cientistas homens citam mais publicações de autores que publicações de autoras, a partir da análise de mais de mil artigos científicos publicados entre 1991 a 2005. Rossiter (1993) identificou um fenômeno ao análogo ao Efeito Mateus (Merton, 1968), segundo o qual cientistas eminentes recebem mais crédito que pesquisadores comparativamente menos conhecidos. Ela identificou que mulheres cientistas recebem menos crédito pelo seu trabalho do que lhes caberia por meio de um exame imparcial de seu trabalho e chamou este fenômeno de "Efeito Matilda", em homenagem à ativista norte-americana Matilda J. Gage, que chamou atenção para o viés de gênero que ocultava as contribuições das mulheres inventoras, ainda no final do século XIX. Estes estudos contribuem para a construção de métricas $e$ indicadores desagregados por gênero que, além do diagnóstico, podem orientar a concepção e planejamento de políticas públicas 
ou programas e projetos que visem à redução ou eliminação da inequidade de gênero na ciência e tecnologia (Leta, 2003; Lopes; Piscitelli, 2004; Melo; Oliveira, 2006).

A situação das mulheres nas carreiras científicas é marcada por uma segregação multidimensional: a segregação horizontal, associada à feminização persistente em áreas como Saúde e Educação, Humanidades e Ciências Sociais (Keller, 1985); a segregação vertical, que resulta na concentração de mulheres em posições intermediárias ou inferiores da carreira científica e na constatação de que as mulheres recebem menos financiamento do que os homens e; a segregação institucional expressa na presença feminina deficitária nas instituições de prestígio e no grande número de pesquisadoras em empregos de tempo parcial ou com vínculos instáveis. A segregação multidimensional alimenta o fenômeno do "teto de vidro", uma metáfora para estruturas formais e preconceitos subjacentes que criam obstáculos relativos ao acesso e progressão feminina nas carreiras científicas, nas altas hierarquias organizacionais e nos setores mais lucrativos da economia (Lewis, 2014).

Ecklund, Lincoln e Tansey (2014) identificam explicações de "oferta" e "demanda" para as disparidades de gênero em campos científicos. Por "oferta" os autores referem-se à distribuição desigual de mulheres e homens nos cursos de formação superior e aos padrões de socialização que retratam as carreiras STEM como pouco atraentes para as mulheres, encorajando-as a migrar para outras áreas que não se oponham às normas de gênero convencionais. As explicações relativas à "demanda", referem-se às próprias condições de trabalho no ambiente acadêmico, caracterizadas pelas longas horas de dedicação à pesquisa, aos horários nem sempre convencionais do trabalho em laboratório e às demandas crescentes por publicação, citação e financiamento, que não proporcionam um ambiente que possibilite a combinação de trabalho remunerado e cuidados parentais.

A segregação profissional reproduz disparidades de renda, autonomia, oportunidades de emprego e ascensão hierárquica (Fox; Sonnert; Ninkiforova, 2011). No Reino Unido, Walby (2011) 
analisou como se manifesta a segregação de gênero nas profissões associadas à "economia do conhecimento" e concluiu que embora as mulheres tenham obtido maiores qualificações educacionais nas últimas décadas, o impacto não foi significativo no número de empregos ocupados por elas nas carreiras da tecnologia da informação, pois persiste uma segregação de gênero no sistema de educação. As mulheres graduadas nas formações mais bem remuneradas pela economia do conhecimento são minoria, ao mesmo tempo em que os trabalhos nas áreas de Educação e Humanidades, qualificações majoritariamente adquiridas pelas mulheres, recebem menores salários.

No campo da tecnologia da informação, diversas fontes apontam que a subrepresentação das mulheres é um fenômeno mundial. Em 2004, a Information Technology American Association (ITAA) indicou que a força de trabalho feminina empregada em TI, nos EUA, país que tem a maior proporção de mulheres neste setor, correspondia a $32,4 \%$ do total de empregos. De lá para cá, esta proporção decresceu. Em 2013, a proporção de mulheres empregadas no setor, nos EUA, correspondia a $25 \%$ do total da força de trabalho (Bohr, 2013). No Canadá, as mulheres constituem $50,4 \%$ da população do país e $47,2 \%$ da força de trabalho. No entanto, o número de mulheres empregadas no setor de TI está estimado em apenas 21\% (Beyer, 2014).

$\mathrm{Na}$ Índia, as mulheres representavam apenas $14 \%$ da força de trabalho na indústria de tecnologia da informação, em 2006 (Pande, 2006). No Reino Unido, as mulheres detêm $15 \%$ dos postos de trabalho da área, proporção semelhante à registrada para a União Europeia, segundo Hunter (2012). Em 2012, as mulheres representavam de $19 \%$ a $25 \%$ dos trabalhadores da área na Austrália (Australian-Computer-Society, 2012), enquanto estudos na Nova Zelândia indicaram que as mulheres são menos remuneradas do que seus colegas homens atuantes na área, recebendo salários $23 \%$ menores, em funções equivalentes (Belgorodskiy et alii, 2012). Na Alemanha, o levantamento do gênero dos fundadores de empresas de base tecnológica constatou que as mulheres correspondem a apenas $16 \%$ deste segmento, 
bem como são minoria entre programadores e desenvolvedores de software (Dautzemberg, 2012) .

Nos EUA, segundo a National Science Foundation (NSF), a Ciência da Computação é o único curso de graduação das áreas STEM que experimentou um declínio significativo na representação feminina, com apenas $22,3 \%$ dos títulos de bacharel conferidos a mulheres (NSF, 2013). Em 2013, apenas 0,4\% das estudantes do primeiro ano pretendiam ingressar em disciplinas de habilitação (majors) da área de computação, percentual sete vezes inferior se comparado aos $2,9 \%$ de seus colegas homens (NSF, 2013). Nem as baixas taxas de adesão ou as altas taxas de evasão são devidas a notas mais baixas das estudantes. Os diagnósticos de Pretorius (2015) e Beyer (2014) não identificaram uma relação direta entre notas $e$ a evasão de mulheres em cursos de computação da África do Sul, Estados Unidos e Canadá.

Estudos que se apoiam em teorias da Psicologia do Trabalho defendem que estereótipos associados às profissões de computação e tecnologia da informação contribuem para exclusão de mulheres e a estigmatização daquelas que atuam no campo. Sustentam que variáveis de natureza psicossocial podem minar o senso de pertencimento ao campo e influenciar negativamente a escolha de um curso ou de uma área de especialização, reforçando os critérios de exclusão, em detrimento das variáveis de atração e autoafirmação (Cundiff et alii, 2013). O senso comum representa o profissional de tecnologia da informação como portador de interesses e repertório restritos à própria profissão, deficiente em habilidades interpessoais, popularmente denominado de nerd, geek ${ }^{2}$, ou hacker, este último relacionado à prática de crimes virtuais.

Ao avaliar a influência de estereótipos sobre o comportamento de estudantes de computação do primeiro ano de graduação, Cheryan, Siy, Vichayapai, Drury e Kim (2011)

\footnotetext{
${ }^{2}$ Expressão idiomática da língua inglesa que faz referência a pessoas com interesse $e$ habilidades em tecnologia, comportamento social introvertido $e$ aparência não convencional (Cheryan et alii, 2011).
} 
concluíram que profissionais que personificam os atributos da cultura geek exercem graus de empatia e inspiração diferentes, entre homens e mulheres. Entre as estudantes, a existência de mulheres bem sucedidas em carreiras de computação exerce um efeito de inspiração, embora tais efeitos sejam reduzidos quando as referidas profissionais encarnam características do estereótipo geek.

Os estereótipos também alimentam a segregação de gênero nas redes de relacionamento profissional, ao estimular práticas informais de socialização que promovem o isolamento social das mulheres (Durbin, 2011). Em seu estudo etnográfico sobre a network de empreendedores de alta tecnologia do Vale do Silício (EUA), Ozkazanc-Pan (2014) conclui que estas redes são predominantemente formadas por homens jovens. Tais redes reproduzem subculturas masculinas e expectativas quanto a papéis tradicionais de gênero em relação à família e o trabalho. As redes dão suporte e acesso privilegiado a informações aos "internos", enquanto manifestam indiferença ou hostilidade aos "externos". No contexto estudado, mulheres de todas as idades $e$ homens sêniores são impelidos a construir suas próprias redes de relacionamento profissional, uma estratégia que reforça o papel do "outro" e os afasta do protagonismo.

A sub-representação do gênero feminino no setor de tecnologia da informação é um problema global que tem consequências de ordem econômica e de justiça social. Ela provoca questionamentos relativos à imparcialidade e à equidade de oportunidades. Uma das consequências de médio prazo seria um "apagão" de recursos humanos qualificados (labor shortage) até 2020, nos EUA, Canadá e em outros países ocidentais, considerando-se os níveis das taxas de crescimento deste setor $e$ sua projeções de expansão (Lockard; Wolf, 2012). Outra consideração a ser feita é que o setor desperdiça a oportunidade de fomentar a pesquisa científica e a inovação ao excluir mulheres potencialmente competentes. Criatividade, descobertas $e$ breakthroughs requerem pensamento original e questionador, o que é estimulado pela diversidade (Herring, 2009). 
No Brasil, análises de gênero em estudos sobre as atividades de pesquisa científica e tecnológica começaram esparsas, tendo experimentado um adensamento gradual, nos últimos anos. Algumas das principais preocupações destes estudos são: o acesso das mulheres à educação superior $e$ às profissões científicas $e$ técnicas (Azevedo; Ferreira, 2006; Osada; Costa, 2008; Moreira; Velho, 2010); o resgate de biografias (Sombrio, 2016); a investigação de processos de feminização persistente em campos e carreiras científicas (Lopes; Leal, 2005); o efeito do gênero na concessão de financiamento à pesquisa e no sistema de recompensas da ciência (Guedes; Azevedo; Ferreira 2015), entre outros.

Estudos recentes, como o de Maia (2016), tratam da inserção da mulher nas carreiras ligadas à tecnologia da informação, abordando a presença feminina nos cursos superiores da computação e concluindo que há uma persistência de barreiras de gênero, o que explicaria o aumento do número de homens graduados e o decréscimo do número de mulheres que concluem o curso. Arruda, Bezerra, Neris e Rocha de Torio (2009) abordam a distribuição, por gênero e região, dos pesquisadores brasileiros na área de Ciência da Computação. Concluíram que as cientistas tendem a se concentrar em áreas como sistemas colaborativos $e$ educação, em que ganha destaque a dimensão "humana" da tecnologia, enquanto são menos presentes em áreas em que o componente de engenharia da computação é mais expressivo, tais como hardware e construção de redes.

Mais recentemente, registra-se trabalhos que vão além das dificuldades de acesso das mulheres à área de tecnologia da informação e à distribuição sexual do trabalho neste campo. São trabalhos que tratam: do resgate da trajetória de pioneiras (Schwarcz, 2018); da crítica à reprodução de estereótipos que objetificam e reduzem "a participação de mulheres nas TICs, como no caso das 'musas' " (Paz, 2015:343); do questionamento da atribuição do pensamento computacional como próprio dos homens ou da atribuição de características "femininas" à internet $e$ às mídias sociais (Rocha; Farias; Alencar, 2013); do "ciberfeminismo" e do papel do ativismo coletivo frente à lacuna 
de gênero na tecnologia da informação (Miguel; Boix, 2013); do fomento da participação de meninas em cursos de computação (Nunes et alli, 2017); do mapeamento das expectativas, dificuldades e trajetórias de alunas (Amaral et alli, 2017) e professoras destes cursos (Lima, 2013); da desconstrução do argumento de que ações, projetos e programas de equidade de gênero são discriminatórios e não meritocráticos ( $\mathrm{Paz}, 2015)$.

Persiste uma lacuna, no entanto, no que diz respeito ao diagnóstico da participação de mulheres na pesquisa científica sobre a Tecnologia da Informação, área mais ampla que abarca o conjunto de atividades e soluções referentes à produção, armazenamento, disseminação, segurança, gestão e uso da informação. É a esta problemática que este trabalho se dirige, com o objetivo de caracterizar a natureza da participação feminina nos grupos de pesquisa sobre Tecnologia da Informação cadastrados no Diretório dos Grupos de Pesquisa do CNPq (DGP-CNPq), respondendo às seguintes questões: quantas são; que posições ocupam nestes grupos (se estudantes, técnicas, pesquisadoras, líderes); em que áreas e subáreas de conhecimento estão presentes; onde estão ausentes e; que lugar ocupam no sistema de recompensa de seu campo de atuação, aferido pelo número de mulheres contempladas com bolsas de produtividade em pesquisa do CNPq. Adicionalmente, com o intuito de complementar os dados colhidos no DGP-CNPQ, foi feito um estudo bibliométrico de teses e dissertações sobre Tecnologia da Informação, disponíveis na Biblioteca Digital Brasileira de Teses e Dissertações do Instituto Brasileiro de Informação em Ciência e Tecnologia (BDTD/IBICT) com a finalidade de analisar a variável "gênero", relacionada aos seguintes parâmetros: série temporal do número de teses e dissertações segundo gênero dos autores e orientadores; gênero dos orientadores mais frequentes; relação entre gênero dos autores e orientadores dos trabalhos.

Além desta introdução, em que é apresentado o objetivo do trabalho, bem como a discussão teórica com o qual dialoga, este artigo é composto de mais cinco sessões. Na sessão 2, é descrito o percurso metodológico para a realização da coleta, sistematização 
e análise dos dados empíricos. Na sessão 3 são apresentados e discutidos os dados relativos à participação das mulheres nos grupos de pesquisa sobre TI e na produção de teses e dissertações, frente aos conceitos teóricos adotados. Finalmente, na sessão 4 são expostas as considerações finais dos autores e sugestões para futuros trabalhos.

\section{Procedimentos metodológicos}

A abordagem de pesquisa deste trabalho é exploratória e quantitativa, combinando dois procedimentos: o estudo da participação feminina nos grupos de pesquisa sobre Tecnologia da Informação cadastrados e atualizados no DGP-CNPq, segundo dados do censo realizado em 2014 e; o estudo bibliométrico de teses e dissertações sobre Tecnologia da Informação, disponíveis na Biblioteca Digital Brasileira de Teses e Dissertações do Instituto Brasileiro de Informação em Ciência e Tecnologia (BDTD/IBICT). O DGP-CNPq ${ }^{3}$ foi definido como fonte de dados por seu caráter institucional, sua abrangência e controle de atualização dados, enquanto a Plataforma Lattes foi a acessada devido à necessidade de extração de dados do currículo dos participantes dos grupos de pesquisa. A escolha da BDTD-IBICT justifica-se por se tratar de plataforma que armazena e disponibiliza a versão integral de teses e dissertações defendidas em programas de pós-graduação de instituições brasileiras. Foi aplicada estatística descritiva para síntese, apresentação e interpretação dos dados extraídos de todas as fontes.

Para a coleta de dados no DGP-CNPq foram empregadas as seguintes expressões de busca nos campos "nome do grupo", "nome da linha de pesquisa" e "palavras-chave da linha de pesquisa": "Tecnologia da Informação" e "Tecnologia de Informação". Posteriormente foram excluídos os registros duplicados e descartados os grupos com status diferente de "certificado", chegando-se a uma amostra final de 225 grupos de

3 Disponível em http://lattes.cnpq.br/web/dgp. 
pesquisa. Dado o grande número de dados recuperados e a necessidade de organizá-los para a elaboração das análises estatísticas, foi construído um script (texto com instruções escritas para o computador) com a finalidade de automatizar parcialmente o processo de coleta dos dados no DGP. Executado em maio de 2016, o referido script recuperou os dados dos 225 grupos da amostra e os distribuiu em duas tabelas: uma para os dados dos grupos como um todo (com dados sobre identificação, endereço, linhas de pesquisa, repercussões, recursos humanos, instituições parceiras, equipamentos e softwares) e outra para os dados dos participantes de cada grupo (titulação e data de ingresso no grupo). Para cada participante dos grupos, foi adicionado um campo relativo ao gênero e um campo para a indicação das bolsas usufruídas, quando este participante também exerce a função de líder de grupo. As informações relativas às bolsas de pesquisa, desenvolvimento tecnológico ou extensão foram coletadas na Plataforma Lattes.

Já a coleta de teses e dissertações foi realizada na BDTDIBICT entre os meses de fevereiro e março de 2016. Para recuperar os trabalhos, foram empregadas as expressões de busca "tecnologia de informação" e "tecnologia da informação", nos campos "título" e "assunto". Optou-se pela utilização da busca avançada, obtendo como resultado 2039 teses e dissertações defendidas até dezembro de 2015 e disponíveis em acesso aberto. Desses registros, foram excluídas as repetições $(n=18)$, resultando em um corpus final de 2021 trabalhos. Os dados foram registrados em planilha e analisados mediante parâmetros ou categorias de análise bibliométrica, método que mede e monitora a produção científica, na forma de artigos, teses, dissertações e livros, contribuindo para a produção de indicadores $e$ a descrição do estado da arte da pesquisa científica e da construção do conhecimento (Rossiter, 1993).

O levantamento e a sistematização de dados extraídos do Diretório dos Grupos de Pesquisa do CNPq forneceu um inventário dos grupos de pesquisa científica sobre tecnologia da informação em atividade no país, além de possibilitar a verificação 
de hipóteses de ocorrência de segregação vertical, horizontal ou institucional de mulheres inseridas em tais grupos. Para testar estas hipóteses, os dados foram organizados nas seguintes categorias de análise: gênero dos participantes; gênero das lideranças; titulação dos participantes e financiamento das pesquisas; distribuição dos grupos por região; instituição; ano de formação; áreas e subáreas de conhecimento. Por seu turno, o estudo bibliométrico das teses e dissertações contribuiu para a verificação das hipóteses ao gerar dados referentes à relação entre o gênero dos autores $e$ orientadores dos trabalhos e à construção de séries temporais do número de teses e dissertações defendidas, associadas ao gênero dos autores e orientadores.

Cumpre ressaltar o emprego do gênero enquanto categoria analítica, neste trabalho. A distinção entre sexo e gênero é uma das premissas dos estudos feministas. Assim, o sexo seria referente a condições biológicas inatas, enquanto a identidade de gênero corresponderia uma distinção sociológica, referente a um papel social. A cada um de nós seria atribuído um gênero no nascimento $e$ às atribuições de gênero correspondem um conjunto de expectativas transmitidas e papéis sociais.

Mas as ideias sobre masculino e feminino não são termos fixos, não estão postas e variam de acordo com cada cultura $e$ época, razão pela qual Butler adverte para o risco de determinismo cultural

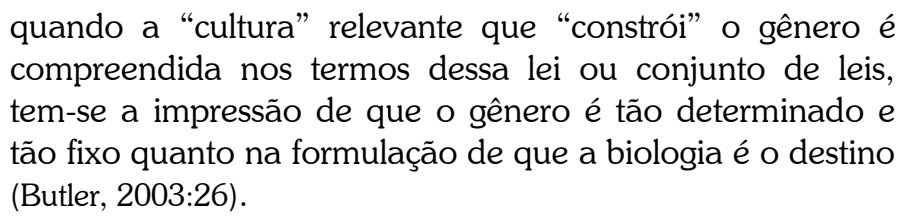

A autora questiona a suposta unidade da categoria "mulheres" na teoria feminista e argumenta que também o sexo não é natural, mas discursivo, como o gênero (Rodrigues, 2005). De forma análoga, Scott (1995) em célebre artigo sobre a discussão de gênero como categoria analítica, questiona os usos descritivos do 
gênero $e$ a dualidade entre sexo, dado pela natureza e gênero, determinado pela cultura. Propõe o conceito de gênero como a percepção, o saber sobre as diferenças sexuais, incluindo os sentidos dados às relações sociais e de poder.

Dado que as fontes consultadas - DGP-CNPq, Plataforma Lattes e BDTD-IBICT - não apresentam a distinção de gênero associada ao nome dos pesquisadores, autores $e$ orientadores $e$ que o uso de nome social em sistemas de informação da administração pública federal é reconhecido no artigo 3o. do Decreto 8727/2016 (Brasil, 2016a), não sendo, por exemplo, explicitada a condição de participante transgênero nas referidas plataformas, optou-se pelo uso da categoria "gênero" na apresentação de indicadores relativos à participação feminina $e$ masculina, por ser mais abrangente que a categoria "sexo". Além disso, entende-se que a participação lacunar das mulheres na tecnologia da informação, já diagnosticada e demonstrada com dados na literatura internacional e alguma literatura nacional mais recente, justifica a proposição de um estudo com o propósito de caracterizar, qualitativa e quantitativamente, qual a natureza de sua presença na pesquisa científica sobre o tema, o que não significa aderir a uma perspectiva exclusivamente binária ou desconhecer a crítica à dualidade sexo/gênero nos estudos feministas. Entende-se que este diagnóstico é oportuno para verificação de hipóteses de segregação vertical ou horizontal, produzir indicadores, orientar ações de política científica e/ou programas, projetos e ações em prol da equidade de gênero na tecnologia da informação. A seguir, apresentamos e analisamos os resultados obtidos após a coleta e sistematização dos dados.

\section{Apresentação e discussão dos resultados}

Participação feminina nos grupos de pesquisa sobre tecnologia da informação

Todos os participantes dos grupos de pesquisa registrados no DGP-CNPq estão cadastrados em uma das seguintes categorias: 
colaboradores estrangeiros ${ }^{4}$, estudantes ${ }^{5}$, estudantes egressos ${ }^{6}$, pesquisadores ${ }^{7}$, pesquisadores egressos e técnicos. O Gráfico 1 apresenta o resultado da distribuição por gênero nas categorias $e$ mostra que a participação feminina é minoritária entre os colaboradores estrangeiros, estudantes, pesquisadores $e$ pesquisadores egressos, sendo majoritária apenas entre os técnicos e estudantes egressos.

Gráfico 1: Gênero dos participantes dos grupos de pesquisa em tecnologia na informação

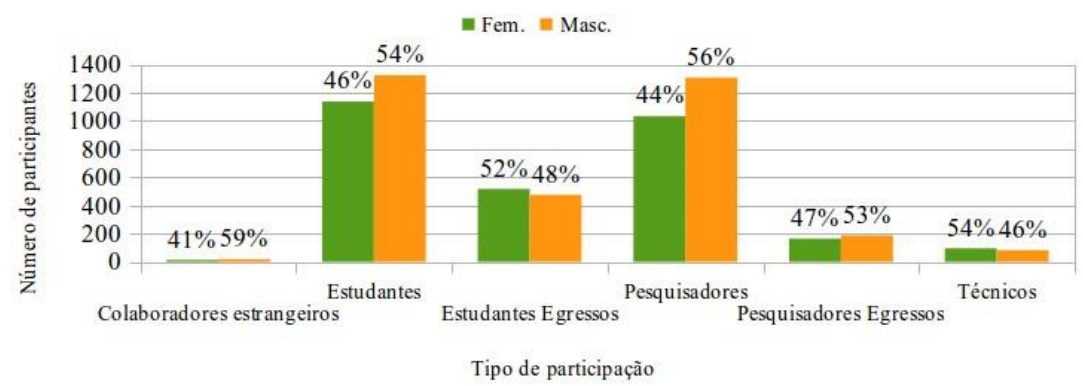

Fonte: Elaboração própria.

${ }^{4}$ É o pesquisador estrangeiro, não residente no Brasil, que colabora eventualmente com o grupo (Brasil, 2016b).

${ }^{5}$ É estudante em iniciação científica ou em cursos de pós-graduação que participa ativamente de linhas de pesquisa desenvolvidas pelo grupo, sob a orientação de pesquisadores do grupo. Estagiários em nível de pósdoutoramento são considerados pesquisadores do grupo e não estudantes. (Brasil, 2016b).

${ }^{6}$ Corresponde ao pesquisador ou o estudante que dele já participou (Brasil, 2016b).

7 É um membro graduado ou pós-graduado da equipe de pesquisa, envolvido com a realização de projetos e com a produção científica, tecnológica e artística do grupo (Brasil, 2016b). 
São dados que endossam a literatura internacional sobre a masculinização do campo da tecnologia da informação e que indicam a manifestação de segregação vertical nos grupos de pesquisa brasileiros, visto que técnicos correspondem a um perfil normalmente associado a tarefas de apoio ou cumprimento de rotinas operacionais. Adicionalmente, a superioridade do percentual de estudantes egressas (54\%) em relação ao percentual de estudantes egressos (48\%) e de pesquisadores (56\%) em detrimento das pesquisadoras (44\%) sugerem uma hipótese a ser testada: a de que um percentual não desprezível de estudantes egressas não é absorvido ou atraído pela pesquisa acadêmica em tecnologia da informação. Do contrário, os percentuais entre os gêneros seriam mais equitativos na categoria "pesquisadores".

Indícios de segregação vertical também emergem da análise da distribuição por gênero dos líderes dos grupos. $\mathrm{O}$ pesquisador líder de um grupo é "o personagem que detém a liderança acadêmica e intelectual no seu ambiente de pesquisa" (Brasil, 2016b). Tem a responsabilidade de coordenação e planejamento dos trabalhos de pesquisa do grupo, aglutinando esforços, definindo linhas de pesquisa e propondo novas áreas de atuação. Um grupo pode admitir até dois líderes, denominados de primeiro e segundo líder, não havendo uma relação hierárquica entre estes. Nos grupos de pesquisa em Tecnologia da Informação, o total de grupos com liderança masculina $(n=150)$ é exatamente o dobro do total de grupos com liderança feminina $(n=75)$, conforme exposto no Gráfico 2. Ainda que o número de pesquisadores cadastrados nos grupos seja $12 \%$ superior ao número de pesquisadoras, este percentual não é suficiente para justificar uma discrepância de 50\% em relação ao gênero dos líderes dos grupos. 
Gráfico 2: Gênero das lideranças dos grupos em tecnologia da informação

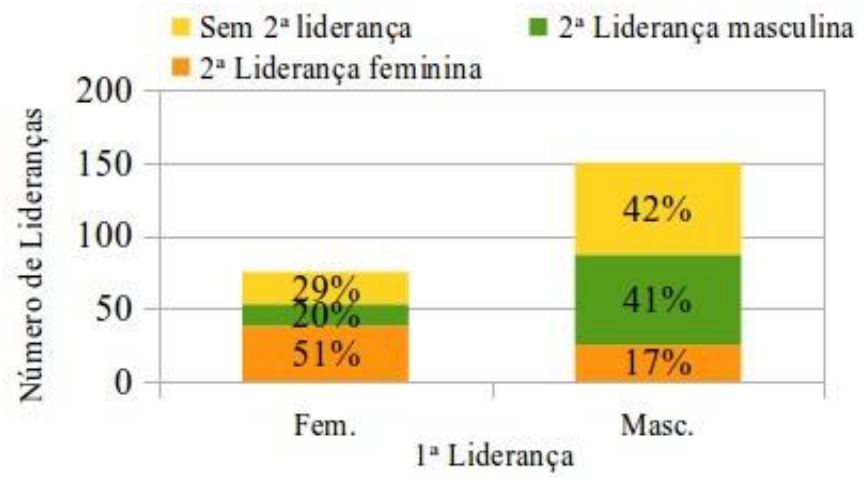

Fonte: Elaboração própria

Foi verificado que os grupos com liderança mista, composta por mulheres e homens, correspondem a $37 \%$ do total e que a ocorrência de grupos com liderança compartilhada é maior entre as mulheres. Nos grupos em que o primeiro líder é uma mulher, $51 \%$ têm outra mulher como segundo líder, $29 \%$ não tem segundo líder e $20 \%$ tem um homem como segundo líder. Quando o primeiro líder do grupo é um homem, em $42 \%$ dos grupos não há segunda liderança, há outro homem com segundo líder em $41 \%$ dos grupos e uma mulher como segundo líder em apenas $17 \%$ dos grupos.

A participação masculina é majoritária tanto em grupos liderados por homens, quanto em grupos liderados por mulheres (Gráficos 3 e 4), sendo que o número de participantes do gênero feminino é superior nos grupos liderados por mulheres $(38 \%$ dos participantes), sugerindo a investigação da hipótese de que a inclusão de mulheres na pesquisa sobre tecnologia da informação pode ser maior nos grupos em que a liderança é feminina. 
Gráfico 3: Gênero dos participantes em grupos de pesquisa em tecnologia da informação com liderança masculina

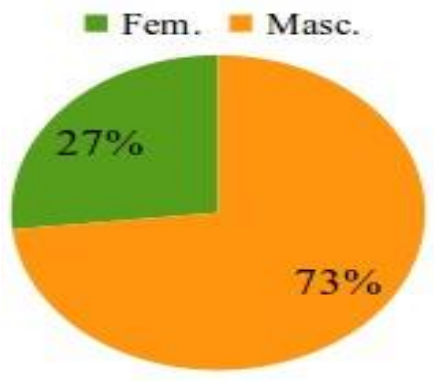

Fonte: Elaboração própria.

Gráfico 4: Gênero dos participantes em grupos de pesquisa em tecnologia da informação com liderança feminina

E Fem. $=$ Masc.

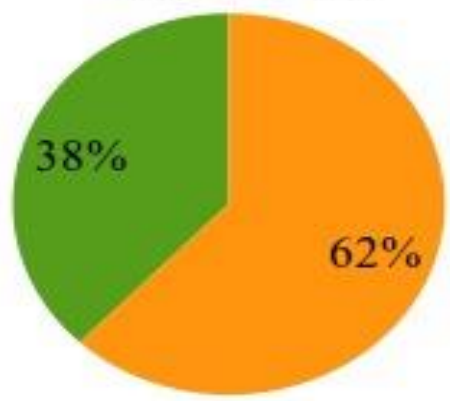

Fonte: Elaboração própria.

A análise do gênero dos participantes e líderes, mediante a distribuição geográfica dos grupos, revela que a participação feminina é minoritária nos grupos de todas as regióes do Brasil, tanto em relação ao total de participantes, quanto em relação ao total de líderes (Gráficos 5 e 6). A menor participação feminina em grupos de pesquisa de tecnologia da informação está no Sudeste (45\% de participantes) e a maior, no Centro-oeste $(49 \%$ de 
participantes). As regiões Norte e Centro-Oeste apesentam os menores percentuais de mulheres líderes $(25 \%$ e $21 \%$, respectivamente) em grupos de pesquisa da área, enquanto o maior percentual de liderança feminina na pesquisa em tecnologia da informação está na região Nordeste (39\%). Não foi verificada a ocorrência de uma relação direta entre o número de mulheres participantes dos grupos de pesquisa de uma dada região e a presença mais expressiva de lideranças femininas nos grupos da mesma região.

Gráfico 5: Gênero dos participantes dos grupos de pesquisa em tecnologia da informação por região

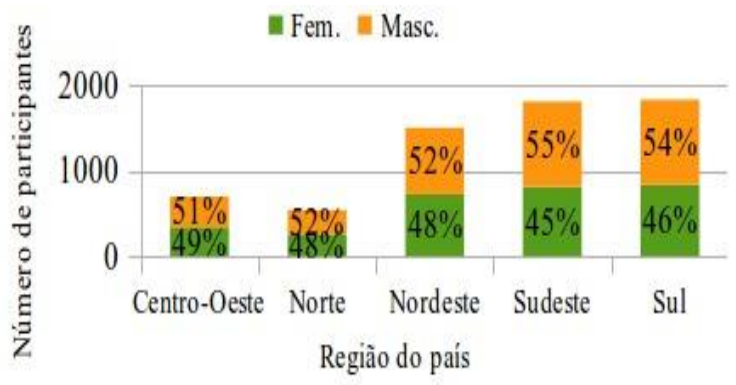

Fonte: Elaboração própria

Gráfico 6: Gênero dos líderes dos grupos de pesquisa em tecnologia da informação por região

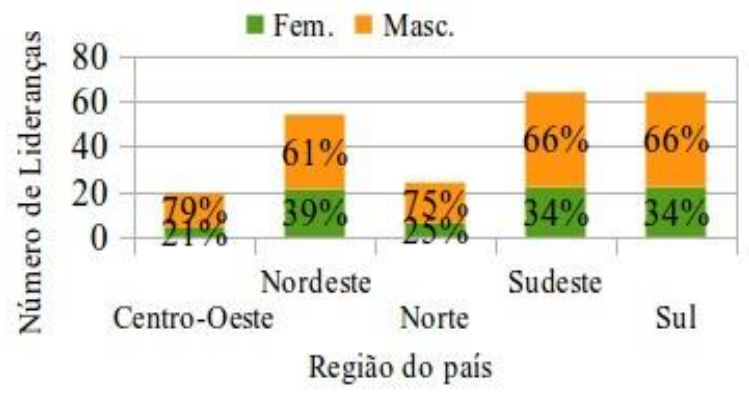

Fonte: Elaboração própria. 
Foram identificadas vinte e três instituições com pelo menos três grupos de pesquisa em tecnologia da informação ativos no DGP-CNPq, vinte oito instituições com dois grupos e sessenta $e$ seis instituições com apenas um grupo de pesquisa ativo na área, totalizando 225 grupos de pesquisa, distribuídos em noventa e quatro instituições. A Tabela 1 apresenta a distribuição dos grupos de pesquisa nas instituições com pelo menos três grupos, bem como o gênero dos líderes destes grupos. 
Tabela 1: Grupos de pesquisa em tecnologia da informação por instituição $e$ gênero dos líderes

\begin{tabular}{llcccc}
\hline Instituição & UF & \multicolumn{2}{c}{ Líderes } & Total \\
\cline { 3 - 5 } & & Mulheres & Homens & \\
\hline Universidade Federal de Santa Catarina (UFSC) & SC & 6 & 3 & 9 \\
Instituto Federal de Santa Catarina (IFSC) & SC & 2 & 4 & 6 \\
Universidade Estadual de Campinas (UNICAMP) & SP & 3 & 3 & 6 \\
Instituto Federal de Educação, Ciência e Tecnologia do Tocantins & TO & 0 & 6 & 6 \\
(IFTO) & & & & \\
Universidade Federal da Paraíba (UFPB) & PB & 3 & 3 & 6 \\
Universidade Federal do Paraná (UFPR) & PR & 2 & 3 & 5 \\
Universidade Federal Fluminense (UFF) & RJ & 3 & 2 & 5 \\
Universidade de Brasilia (UnB) & DF & 1 & 4 & 5 \\
Universidade Federal de Mato Grosso (UFMT) & MT & 1 & 4 & 5 \\
Fundação Oswaldo Cruz (FIOCRUZ) & RJ & 2 & 2 & 4 \\
Instituto Federal de São Paulo (IFSP) & SP & 2 & 2 & 4 \\
Universidade de São Paulo (USP) & SP & 0 & 4 & 4 \\
Universidade Federal de Minas Gerais (UFMG) & MG & 2 & 2 & 4 \\
Universidade Federal de São Carlos (UFSCAR) & SP & 0 & 4 & 4 \\
Instituto Federal de Educação, Ciência e Tecnologia do Rio Grande & RN & 0 & 4 & 4 \\
do Norte (IFRN) & & & & 4 \\
Universidade Federal de Pernambuco (UFPE) & PE & 1 & 3 & 4 \\
Universidade Federal do Ceará (UFC) & CE & 3 & 1 & 4 \\
Universidade do Estado de Santa Catarina (UDESC) & SC & 1 & 2 & 3 \\
Universidade do Vale do Rio dos Sinos (UNISINOS) & RS & 1 & 2 & 3 \\
Universidade Estadual do Centro-Oeste (UNICENTRO) & PR & 0 & 3 & 3 \\
Universidade Tecnológica Federal do Paraná (UTFPR) & PR & 1 & 2 & 3 \\
Instituto Brasileiro de Informações em Ciência e Tecnologia (IBICT) & RJ & 3 & 0 & 3 \\
Instituto Federal de Pernambuco (IFPE) & & 2 & 1 & 3 \\
Total & & 39 & 64 & 103 \\
\hline
\end{tabular}

Fonte: Elaboração própria. 
A instituição com o maior número de grupos de pesquisa em tecnologia da informação, ativos no DGP-CNPq, é a Universidade Federal de Santa Catarina $(n=9)$, que é também aquela onde foi encontrado o maior número de grupos com liderança feminina $(n=6)$. No cômputo geral, a distribuição da liderança dos grupos entre homens e mulheres é desigual. Dentre a vinte e três instituições com o maior número de grupos ativos no DGP-CNPq, foram contabilizados sessenta e quatro homens na posição de liderança, em contraposição a trinta e nove mulheres. Há cinco instituições onde não há grupos com liderança feminina: USP; UFSCar; IFTO; UNICENTRO e IFRN. A única instituição em que não há grupos com liderança masculina é o IBICT, cujos grupos e linhas de pesquisa são majoritariamente ligados às áreas de Biblioteconomia e Ciência da Informação.

Os Gráficos 7 e 8 apresentam séries temporais que relacionam os dados sobre o gênero dos líderes (Gráfico 7) e dos participantes (Gráfico 8), ao ano de criação dos grupos. O registro de criação do primeiro grupo de pesquisa em tecnologia da informação no Brasil remete à década de 1970, enquanto o segundo grupo foi criado na década de 1980. A partir dos anos 1990, há uma aceleração no número de grupos criados e entre os anos 2000 e 2009 o total de grupos $(n=75)$ é cinco vezes maior que o da década anterior $(n=15)$. Entre 2010 e 2016, a base corrente recebeu o registro de 133 novos grupos, o que mostra que a pesquisa em tecnologia da informação no Brasil foi exponencialmente ampliada, pois neste período foram criados quase $60 \%$ dos atuais grupos. 
Gráfico 7: Gênero dos líderes dos grupos de pesquisa em tecnologia da informação x período de criação dos grupos

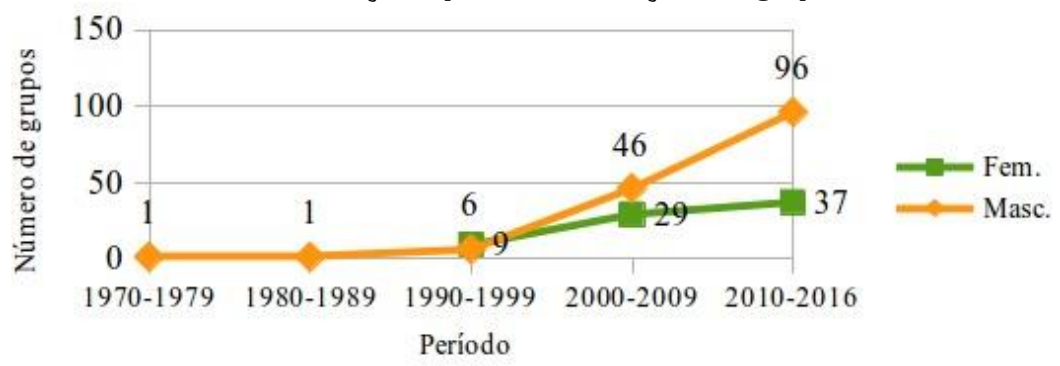

Fonte: Elaboração própria.

Os dados também confirmam que o crescimento do número de grupos de pesquisa em tecnologia da informação foi acompanhado pela masculinização do campo. Os registros das primeiras lideranças femininas em grupos de pesquisa da área surgem apenas na década de 1990, sendo o período 1990-1999 o único em que o número de grupos liderados por mulheres $(n=9)$ foi superior ao número de grupos liderados por homens $(n=6)$. A partir dos anos 2000, a diferença entre o número de grupos com liderança masculina e feminina foi significativamente ampliada em favor dos primeiros. No período 2000-2009, a razão entre o número de grupos liderados por homens $(n=46)$ e por mulheres $(n=29)$ era de 1,58. Entre 2010 e 2016, esta razão já é de 2,59 (96/37).

Quanto à distribuição dos participantes por gênero, ao longo dos anos (Gráfico 8), os dados apontam que nas duas primeiras décadas, entre 1970 e 1989, a maioria masculina é absoluta, ainda que a diferença tenha decrescido significativamente nos vinte anos posteriores: entre 1990 e 1999, as mulheres somavam 47\% $(n=260)$ dos integrantes grupos e entre 2000 e 2009, cerca de 49\% $(n=1278)$. No entanto, a partir de 2010 , o total de participantes do gênero feminino nos grupos de pesquisa em tecnologia da informação decresceu, correspondendo a $45 \%$ dos membros dos grupos em 2016, cabendo o acompanhamento da série temporal para verificar se a tendência de ampliação da disparidade de 
gênero na composição dos grupos será mantida, reduzida ou eventualmente revertida.

Gráfico 8: Gênero dos participantes dos grupos de pesquisa em tecnologia da informação x período de criação dos grupos

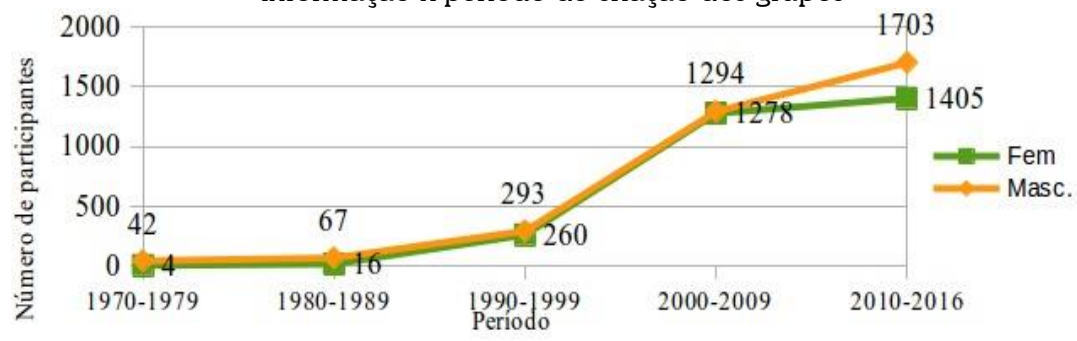

Fonte: Elaboração própria

A hipótese de ocorrência de segregação horizontal associada ao gênero foi testada mediante a análise da distribuição dos grupos de pesquisa por área e subárea de conhecimento, vis a vis o gênero dos líderes e participantes dos grupos. A distribuição dos grupos por área predominante de conhecimento ${ }^{8}$ e subáreas ${ }^{9}$, está representada nos Gráficos 9 e 10, respectivamente. Os percentuais referem-se ao total de grupos identificados em cada área ${ }^{10}$.

${ }^{8}$ É a área do conhecimento que mais se aproxima das atividades de pesquisa do grupo, dentre as existentes na classificação de áreas do conhecimento utilizada pelo CNPq (Brasil, 2016b).

9 Áreas de conhecimento presentes nas áreas predominantes.

${ }^{10} \mathrm{Um}$ por cento dos grupos tem como áreas predominantes as Ciências Biológicas e Linguística, Letras e Artes não estão representados no Gráfico 9. 
Gráfico 9: Áreas de conhecimento dos grupos de pesquisa em tecnologia da informação

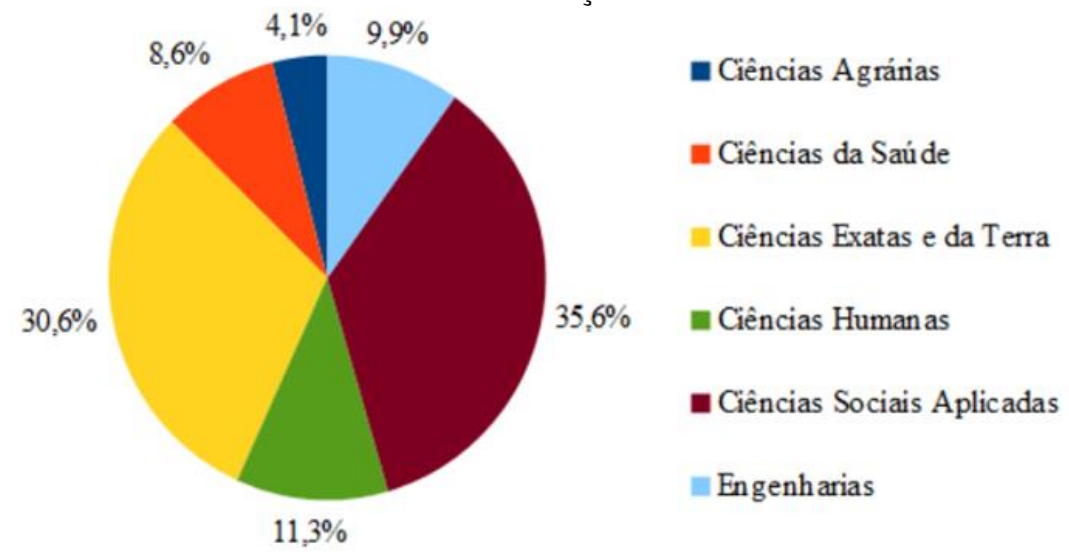

Fonte: Elaboração própria.

A distribuição dos grupos por área predominante de conhecimento (Gráfico 9) indica que a pesquisa sobre tecnologia da informação tem natureza multidisciplinar, visto que existem grupos de pesquisa em todas as áreas do conhecimento e não apenas naquelas próximas ao eixo STEM. A maioria dos grupos está situada nas áreas de Ciências Sociais Aplicadas (35,6\%), seguida das áreas de Ciências Exatas e da Terra (30,6\%). As linhas de pesquisa cobrem um amplo espectro de temas, de "Avaliação de sistemas de informação organizacionais" na Administração, a "Biotecnologia aplicada ao melhoramento de cereais de inverno" na Agronomia, passando por "Tecnologias presenciais e a distância no Ensino na Saúde" na área de Saúde Coletiva.

Para verificar a distribuição dos grupos por subáreas de conhecimento (Gráfico 10), foi aplicado o Princípio de Pareto ${ }^{11}$, que permitiu a identificação das subáreas em que estão concentrados $81,78 \%$ dos grupos. São elas, em ordem decrescente, de acordo com o número de grupos encontrados por subárea: Ciência da Computação, Administração, Educação,

${ }^{11}$ Conhecido como regra do "80-20", destaca, em um conjunto de dados, os que são mais representativos da amostra. 
Ciência da Informação, Engenharia de Produção, Saúde Coletiva, Engenharia Civil, Enfermagem, Química, Arquitetura e Urbanismo, Engenharia Elétrica.

Gráfico 10: Subáreas de conhecimento dos grupos de pesquisa em tecnologia da

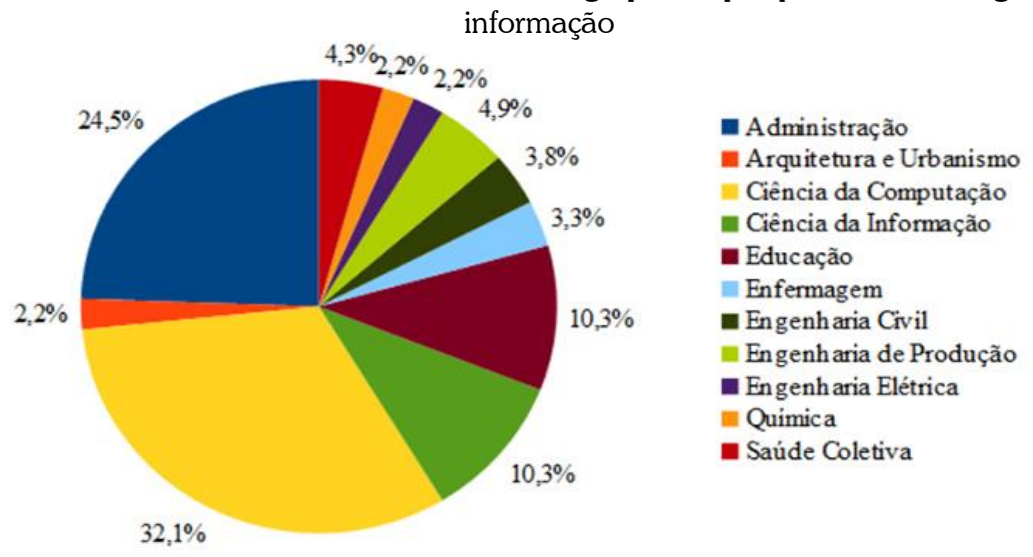

Fonte: Elaboração própria.

É notória a concentração de grupos em duas subáreas de conhecimento: a Ciência da Computação (32,1\%), seguida da Administração (24,5\%). Juntas, estas subáreas representam mais da metade dos grupos $(56,6 \%)$ de pesquisa em tecnologia da informação ativos no DGP-CNPq. Os dados evidenciam uma segunda característica da pesquisa em tecnologia da informação além da anteriormente referida multidisciplinaridade: um perfil de pesquisa aplicada, em estreita associação com a dimensão econômica e com o emprego da tecnologia da informação no setor produtivo. Na Ciência da Computação, predominam os estudos sobre técnicas, metodologia, processos e instrumentos computacionais, enquanto a visão da tecnologia da informação como um recurso de gestão voltado à automação de processos prevalece na área de Administração.

A análise da distribuição dos participantes e líderes dos grupos de pesquisa, por gênero e subáreas de conhecimento 
(Gráficos 11 e 12), indica que a participação e liderança masculina são majoritárias nas duas áreas anteriormente referidas, confirmando evidências de segregação horizontal na pesquisa sobre tecnologia da informação, tanto em número de participantes, quanto na distribuição dos líderes.

Gráfico 11: Gênero dos participantes dos grupos de pesquisa x subáreas de conhecimento

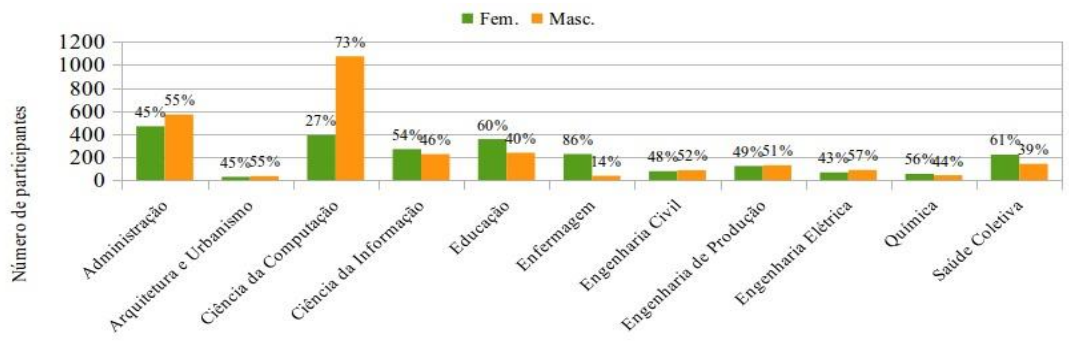

Fonte: Elaboração própria.

Principais subáreas

A segregação horizontal na pesquisa tem sua expressão na concentração de mulheres em áreas e subáreas de conhecimento associadas à prestação de cuidados e educação, por conta de representações sociais tradicionais sobre os atributos, características, competências, interesses e motivações dos homens $e$ das mulheres, no âmbito do trabalho e da família. Além da Computação e Administração, a presença masculina é majoritária nas Engenharias e na Arquitetura e Urbanismo. Por sua vez, a participação feminina é majoritária nas subáreas de Enfermagem, Saúde Coletiva, Educação, Química e Ciência da Informação, nesta ordem (Gráfico 11).

A relação entre o gênero dos líderes $e$ as áreas de conhecimento (Gráfico 12) não difere significativamente da distribuição dos participantes por gênero e área de conhecimento, confirmando a atribuição tradicional de papéis orientados para resultados econômicos e para a competitividade, associados ao 
domínio público, aos homens, e de cuidado e educação às mulheres, mais associados ao domínio privado.

Gráfico 12: Gênero dos líderes dos grupos de pesquisa x subáreas de conhecimento

a Fem. $=$ Masc.

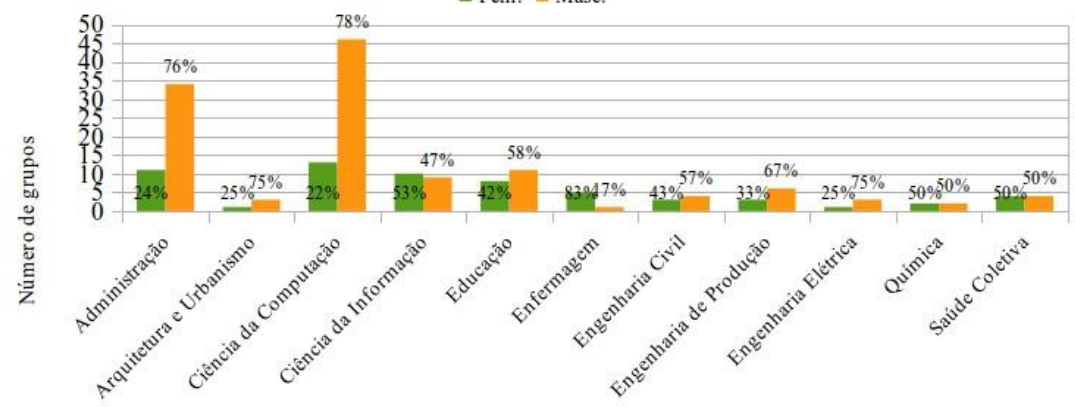

Principais subáreas

Fonte: Elaboração própria.

Os percentuais de mulheres e homens na liderança de grupos são equivalentes apenas nas subáreas de Química e Saúde Coletiva (Gráfico 12). Em todas as outras prevalece a liderança masculina, inclusive e especialmente nas subáreas de Ciência da Computação (78\%) e na Administração (76\%), que concentram a maior parte dos grupos de pesquisa. Os percentuais de liderança feminina predominam nas subáreas de Ciência da Informação (53\%) e Enfermagem (83\%). Ambas são áreas de conhecimento marcadas pela feminização persistente (Lopes e Leal, 2005): a primeira, pela associação com a Biblioteconomia, profissão majoritariamente exercidas em escolas e instituições de ensino (Pagowsky; Rigby, 2014) e a segunda, pela natureza do cuidado e da assistência, ação concebida como feminina e produto das supostas "qualidades naturais" das mulheres (Lopes; Leal, 2005:110).

Nos grupos de pesquisa da subárea Educação, embora o percentual de mulheres seja majoritário (60\%), o percentual de mulheres na liderança dos grupos $(48 \%)$ é inferior ao percentual de homens (58\%). No caso específico dos grupos desta subárea, 
verifica-se a manifestação simultânea da segregação horizontal (concentração de mulheres em área feminizada) e segregação vertical, pois embora sejam numericamente superiores aos homens em termos absolutos, são subrepresentadas nas escalas hierárquicas superiores da comunidade científica.

Os indícios de segregação vertical são reforçados quando analisada a qualificação profissional das mulheres que ocupam as funções de pesquisadoras e técnicas nos grupos de pesquisa, consultando-se os dados do próprio DGP-CNPq, referentes ao nível mais alto de titulação dos membros (Gráficos 13 e 14) ${ }^{12}$. Há mais mulheres na base da hierarquia, visto que apenas nos níveis de graduação (58\%), Mestrado Profissional (58\%) e Especialização, o percentual de mulheres é superior. No topo, equivalente aos pesquisadores com título de Doutorado, a presença feminina ainda é numericamente inferior em $5 \%$, bem como em níveis intermediários, a exemplo do Mestrado Acadêmico, em que o percentual de homens é superior ao de mulheres em $12 \%$.

Gráfico 13: Gênero dos pesquisadores dos grupos de pesquisa x titulação

n Fem. " Masc.

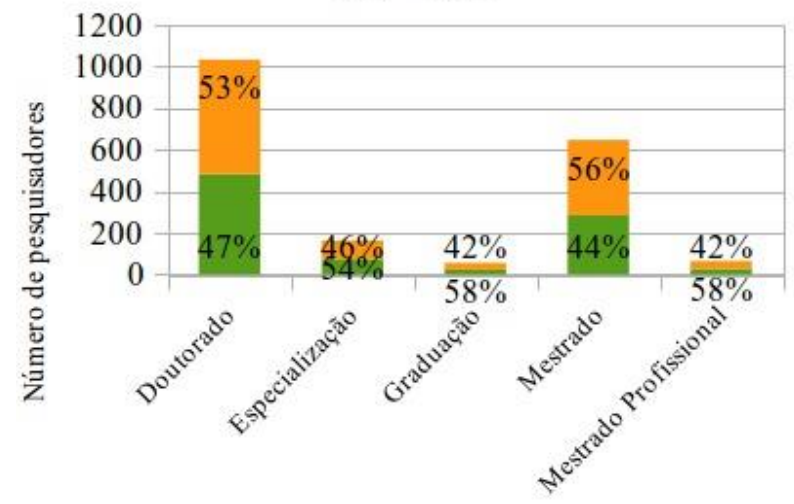

Titulação

Fonte: Elaboração própria

${ }^{12}$ Foram descartados os dados que representavam porcentagens menor ou igual a $1 \%$, em ambos os gráficos. 
A hipótese de segregação vertical ganha robustez quando analisada a titulação mais alta dos técnicos dos grupos de pesquisa, posto que foi constatado que a titulação das mulheres é nitidamente superior à titulação dos homens que ocupam a mesma função (Gráfico 14). A maior parte das técnicas tem título de doutorado (80\%), Especialização (70\%), e Mestrado (55\%), enquanto os homens cadastrados nos grupos como técnicos têm como titulação predominante o Ensino Médio (79\%). Isso significa que um número expressivo de doutoras, especialistas e mestres está cadastrado nos grupos de pesquisa como técnicas, enquanto entre os homens pertencentes à mesma categoria, a formação predominante é o Ensino Médio, seguida pela Graduação.

Gráfico 14: Gênero dos técnicos dos grupos de pesquisa x titulação

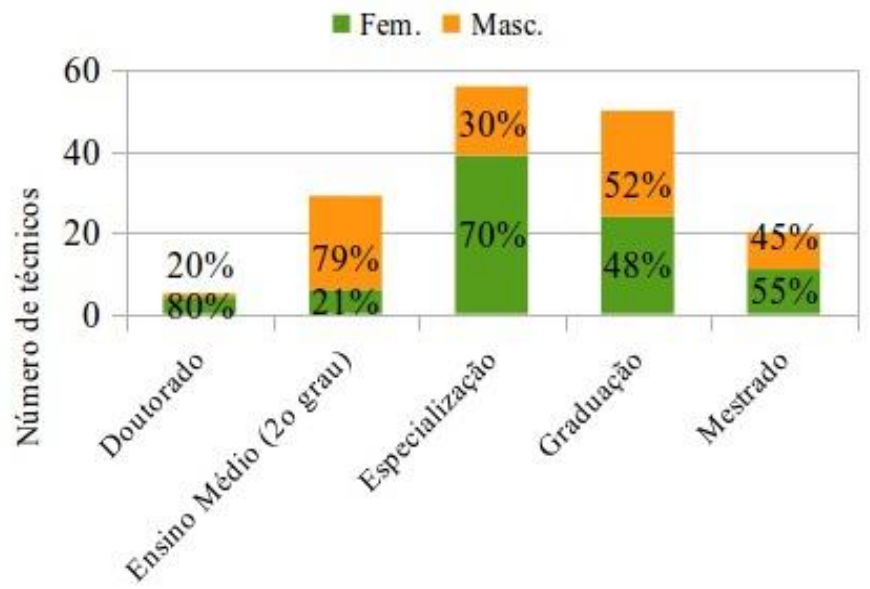

Titulação

Fonte: Elaboração própria. 
Esta discrepância ocorre justamente na categoria em que a maioria absoluta de participantes é de mulheres, que correspondem a $54 \%$ do total de técnicos dos grupos de pesquisa em tecnologia da informação. A razão da dissonância entre a qualificação demandada dos técnicos do gênero feminino $e$ masculino, em detrimento das primeiras, é uma questão que foge ao escopo e aos métodos de investigação aplicados no presente trabalho, o que não nos impede de apontar hipóteses. Uma delas é que um número não desprezível de mulheres com qualificação compatível com o perfil de pesquisadora na área de tecnologia da informação não logram inserção profissional enquanto docentes ou investigadoras em instituições de ensino superior e institutos de pesquisa, sendo absorvidas como técnicas, cabendo investigar porque não ingressam na carreira acadêmica e porque os homens com o vínculo de técnicos têm titulação inferior.

Já entre líderes dos grupos de pesquisa, a relação entre nível de titulação e gênero é inversa da que foi constatada entre técnicos. O percentual de líderes homens é superior ao número de líderes mulheres, seja qual for o nível de titulação considerado: doutorado, mestrado ou especialização (Gráfico 15).

Gráfico 15: Titulação dos líderes dos grupos de pesquisa em tecnologia da informação x gênero

m Fem. $=$ Masc.

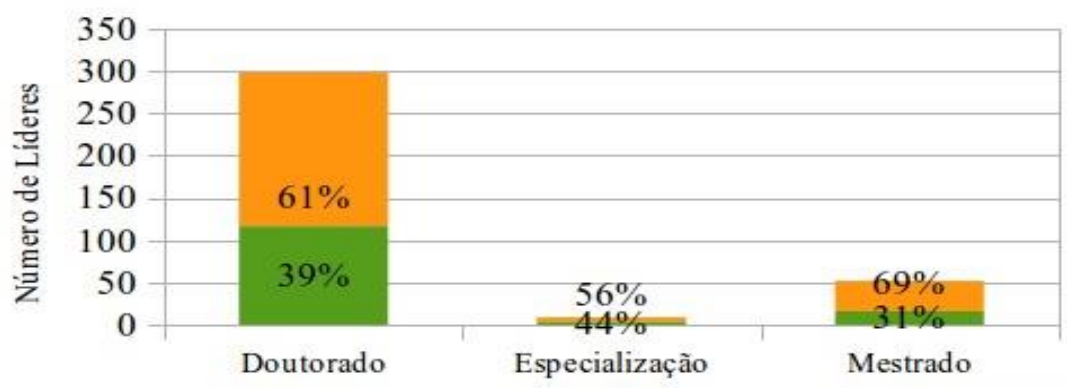

Titulação

Fonte: Elaboração própria 
Quando analisados os percentuais referentes aos níveis de titulação, somente entre os líderes homens (Gráfico 16) e entre as líderes mulheres (Gráfico 17), verifica-se que estes são bem próximos nos três níveis, seja doutorado, mestrado ou especialização. A conclusão é que não há diferenças significativas quanto à titulação de homens e mulheres que são líderes de grupos de pesquisa em tecnologia da informação, mas uma desigualdade de gênero na proporção de grupos com liderança masculina ou feminina, desfavorável aos últimos.

Gráfico 16: Titulação dos líderes dos grupos de pesquisa do sexo masculino

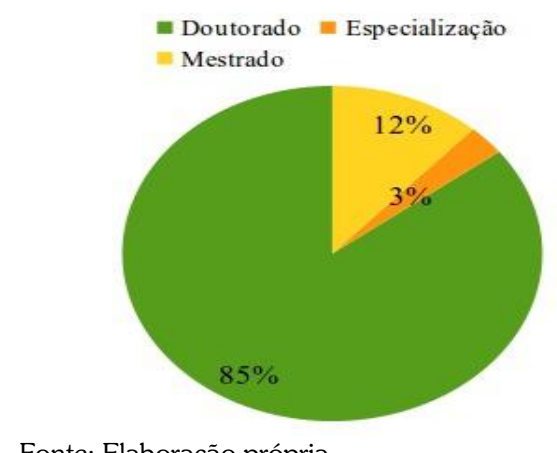

Fonte: Elaboração própria.

Gráfico 17: Titulação dos líderes dos grupos de pesquisa do sexo feminino

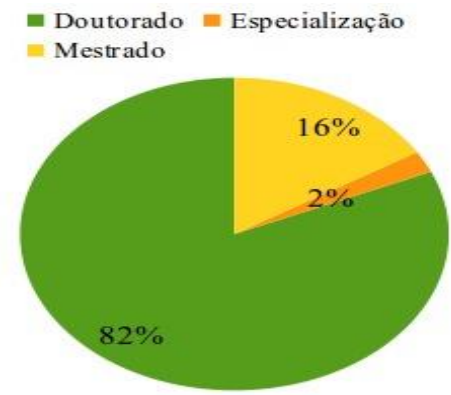

Fonte: Elaboração própria. 
A distribuição desigual da liderança dos grupos de pesquisa entre os gêneros reflete-se na inequidade quanto ao reconhecimento do mérito no sistema de recompensas da ciência $e$ o acesso às fontes de financiamento de pesquisa. Partindo do princípio que as bolsas são, simultaneamente, um mecanismo de financiamento à pesquisa e um signo de reconhecimento dos pares e/ou agências de fomento, foram identificados o número $e$ as modalidades de bolsas recebidas pelos líderes dos grupos de pesquisa em tecnologia da informação, segundo o gênero. Estes dados estão discriminados na Tabela 2.

Tabela 2: Número e tipos de bolsas concedidas aos líderes dos grupos de pesquisa, por gênero

\begin{tabular}{|c|c|c|c|}
\hline Tipos de bolsas ${ }^{13}$ & Mulheres & Homens & Total \\
\hline Bolsista de Apoio Técnico a Pesquisa do CNPq - Nível 1A & 1 & 0 & 1 \\
\hline $\begin{array}{l}\text { Bolsista de Desenvolvimento Tecnológico e Inovação no Exterior Junior } \\
\text { do CNPq }\end{array}$ & 2 & 1 & 3 \\
\hline Bolsista de Desenvolvimento Tecnológico em TIC ${ }^{14}$ do CNPq - Nível A & 0 & 2 & 2 \\
\hline Bolsista de Desenvolvimento Tecnológico Industrial do CNPq - Nível B & 0 & 2 & 2 \\
\hline Bolsista de Extensão no País do CNPq - Nível B & 1 & 0 & 1 \\
\hline Bolsista de Pós-doutorado no Exterior do CNPq & 0 & 1 & 1 \\
\hline $\begin{array}{l}\text { Bolsista de Produtividade Desen. Tec. e Extensão Inovadora do CNPq - } \\
\text { Nível } 2\end{array}$ & 2 & 3 & 5 \\
\hline Bolsista de Produtividade em Pesquisa do CNPq - Nível 1C & 2 & 3 & 5 \\
\hline Bolsista de Produtividade em Pesquisa do CNPq - Nível 1D & 1 & 4 & 5 \\
\hline Bolsista de Produtividade em Pesquisa do CNPq - Nível 2 & 7 & 15 & 22 \\
\hline Total & 16 & 31 & 47 \\
\hline
\end{tabular}

Fonte: Elaboração própria.

\footnotetext{
${ }^{13} \mathrm{~A}$ descrição das bolsas mencionadas nessa tabela pode ser encontrada em: http://cnpq.br/apresentacao13.

${ }^{14}$ Tecnologias da Informação e Comunicação.
} 
O número de bolsas recebidos por mulheres que são lideres de grupos é inferior em todas as modalidades, menos naquelas identificadas com as atividades de apoio técnico, desenvolvimento tecnológico e extensão. A presença feminina é inferior entre os bolsistas de produtividade em pesquisa do CNPq, tanto no Nível 2, onde o número de mulheres bolsistas representa menos de 50\% dos líderes contemplados, como nos estratos superiores desta modalidade, correspondentes ao Nivel $1^{15}$. Vale dizer que a bolsa de produtividade em pesquisa está associada a um dos indicadores mais expressivos do sistema de recompensas da ciência brasileiro, constituindo, simultaneamente, um "instrumento de diferenciação simbólica entre os pares" e um "sistema hierarquizado de posições" (Guedes; Azevedo; Ferreira, 2015:369).

Isso equivale a dizer que a representatividade feminina entre o que pode ser considerada uma elite de pesquisadores em tecnologia da informação no Brasil ainda é modesta se comparada à representatividade masculina, bem como se comparada à proporção de pesquisadoras contempladas com instrumentos de apoio e reconhecimento de atividades de caráter técnico $e$ extensionista. Estes dados, somados às constatações anteriores sobre o alto nível de qualificação das mulheres que exercem as funções de técnicas nos grupos de pesquisa, induzem à reflexão sobre o lugar ocupado pelas mulheres na produção de conhecimento em tecnologia da informação no Brasil. Aparentemente, é mais identificado com a geração de conhecimento técnico e a prestação de serviço (onde também se enquadra a extensão) e menos reconhecido enquanto pesquisa científica, no sentido estrito.

Este resultado reforça a necessidade de construção de indicadores de produção científica, desagregados por gênero, como um recurso válido para o mapeamento da participação feminina em diferentes campos e disciplinas da pesquisa científica

${ }^{15}$ As bolsas do Nível 1 são hierarquizadas, em ordem crescente, em 1D, 1C, 1B e 1A. Não foram encontrados bolsistas $1 \mathrm{~A}$ e $1 \mathrm{~B}$ entre os líderes dos grupos de pesquisa em tecnologia da informação. 
e tecnológica, permitindo o registro de informações baseadas em evidências que possam diagnosticar lacunas, apontar tendências e orientar cursos de ação. Dentre as diferentes possibilidades de mapeamento da produção científica e tecnológica (de artigos, citações, patentes etc.) e com o intuito de verificar qual o espaço das mulheres na produção científica no campo da tecnologia da informação, neste trabalho elegeu-se o levantamento das teses $e$ dissertações defendidas em programas de pós-graduação brasileiros. A coleta foi feita sem aplicação de filtros temporais, com o objetivo de recuperar o maior número de trabalhos na base consultada (BDTD-IBICT) para a construção de indicadores de autoria e orientação, desagregados por gênero. Os indicadores obtidos são apresentados e discutidos na sessão seguinte.

\section{Participação feminina na produção científica de teses e dissertações sobre tecnologia da informação}

Após a coleta dos dados mediante o uso das expressões de busca anteriormente descritos na sessão 2 , todos os nomes de autores e orientadores $(n=4022)$ foram registrados em planilha $e$ desagregados por gênero. A verificação do gênero para nomes de natureza "unissex" foi feita mediante consulta à Plataforma Lattes. A distribuição anual das teses e dissertações defendidas gerou a série temporal representada no Gráfico 18. Dentre os trabalhos recuperados, o mais antigo foi a dissertação do Mestrado em Métodos Quantitativos da Universidade de São Paulo (USP), intitulada "Segurança em Processamento de Dados", de autoria de Edson Luiz Riccio, sob orientação de Nicolau Reinhard, defendida em 1981. Houve crescimento no número de teses e dissertações defendidas, mas não de forma constante e equitativa. A taxa de crescimento é mais acelerada a partir do ano 2000, o que coincide com o incremento do número de grupos de pesquisa na área, registrado na mesma época (Gráficos 7 e 8). 
Gráfico 18: Número de Teses e Dissertações em Tecnologia da Informação: série temporal

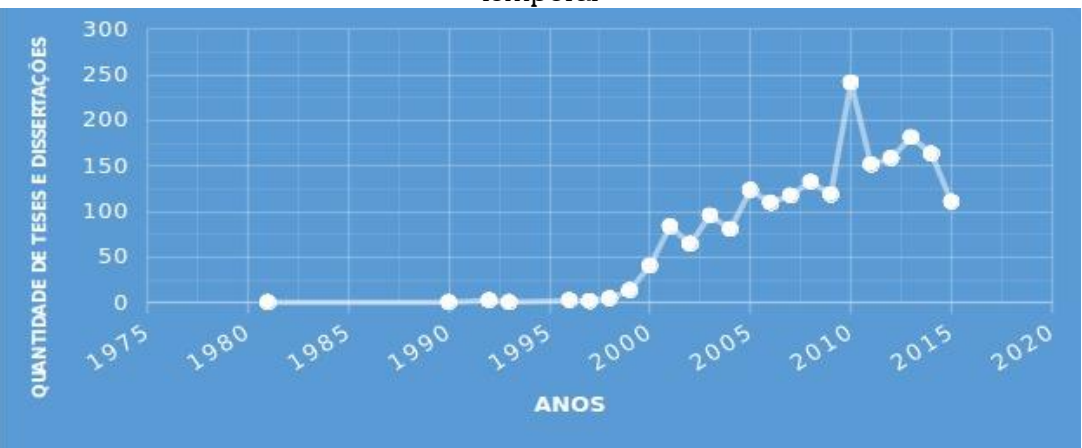

Fonte: Elaboração própria.

As dez instituições com o maior registro de teses $e$ dissertações defendidas foram: Universidade Federal de Santa Catarina $(\mathrm{n}=281)$, que também é aquela com o maior número de grupos de pesquisa na área; Universidade Federal do Rio Grande do Sul ( $n=222)$; Fundação Getúlio Vargas $(n=208)$; Universidade de São Paulo $(n=189)$; Universidade Estadual Paulista $(n=122)$; Universidade Estadual de Campinas $(n=112)$; Universidade Católica de Brasília $(n=99)$; Universidade Federal de Pernambuco $(n=73)$; Universidade Federal de Minas Gerais $(n=68)$ e; Pontifícia Universidade Católica do Rio Grande do Sul $(n=63)$. Corroborando os resultados da busca no DGP-CNPq, referente à multidisciplinaridade dos grupos de pesquisa, estas teses $e$ dissertações foram defendidas em programas de diferentes orientações disciplinares, a exemplo do Programa de PósGraduação em Engenharia de Produção, Programa de PósGraduação em Administração, Programa de Pós-Graduação em Educação e Programa de Pós-Graduação Interdisciplinar em Ciências Humanas.

No total, foram identificados 1123 orientadores, 700 homens e 423 mulheres. Dentre estes, 888 orientaram mais de um trabalho. A análise do gênero de autores e orientadores (Gráficos 19 e 20) confirma que a presença de mulheres é menor que a de homens, tanto em termos de autoria, visto que 43,56\% dos autores são 
mulheres, quanto em termos de orientação, onde a presença feminina corresponde a pouco mais de $35 \%$ dos orientadores.

Gráfico 19: Teses e dissertações segundo o gênero dos autores

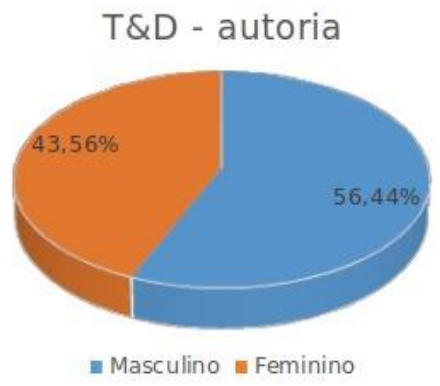

Fonte: Elaboração própria.

Gráfico 20: Teses e dissertações segundo o gênero dos orientadores

$T \& D$ - orientação

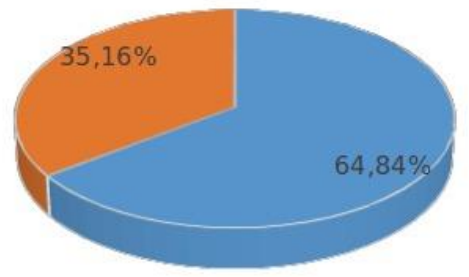

= Masculino $=$ Feminino

Fonte: Elaboração própria.

Os homens são predominantemente orientados por outros homens (798 trabalhos dentre 1135) e minoritariamente orientados por mulheres (337 trabalhos). A coincidência de gênero na relação autoria-orientação não acontece entre as mulheres, que também são majoritariamente orientadas por homens (501 trabalhos dentre 875) e minoritariamente supervisionadas por outras mulheres (374 trabalhos). Ainda que o número de orientadores homens predomine em termos absolutos, a análise da série temporal das teses e dissertações, relacionada ao gênero dos orientadores 
(Gráfico 21), revela que, entre 2010 e 2015, houve uma queda no número de teses e dissertações orientadas por homens, enquanto as teses e dissertações com orientação feminina experimentaram um crescimento gradual.

Gráfico 21: Número de teses e dissertações por ano e gênero dos orientadores

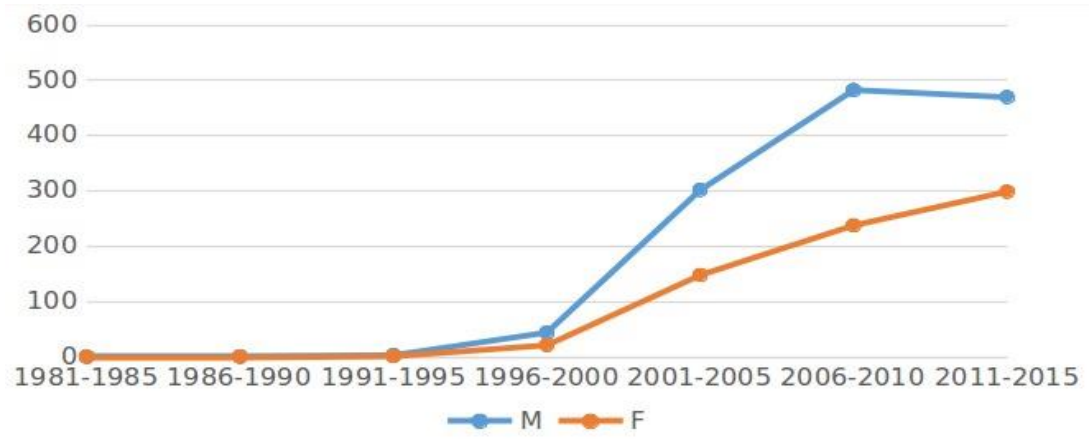

Fonte: Elaboração própria.

A mesma situação ocorre se analisado gênero dos autores, ao longo dos anos. O número de teses e dissertações de autoria masculina $(n=1135)$, é superior ao número de trabalhos de autoria feminina $(n=875)$. Porém, o número de teses e dissertações de autoria masculina caiu a partir de 2010, enquanto a autoria feminina cresceu em ritmo constante (Gráfico 22). Caberá construir e acompanhar novas séries temporais a fim de verificar se as tendências de ampliação de orientação e autoria feminina serão mantidas e qual seu impacto na redução da subrepresentação de gênero na pesquisa brasileira em tecnologia da informação. 


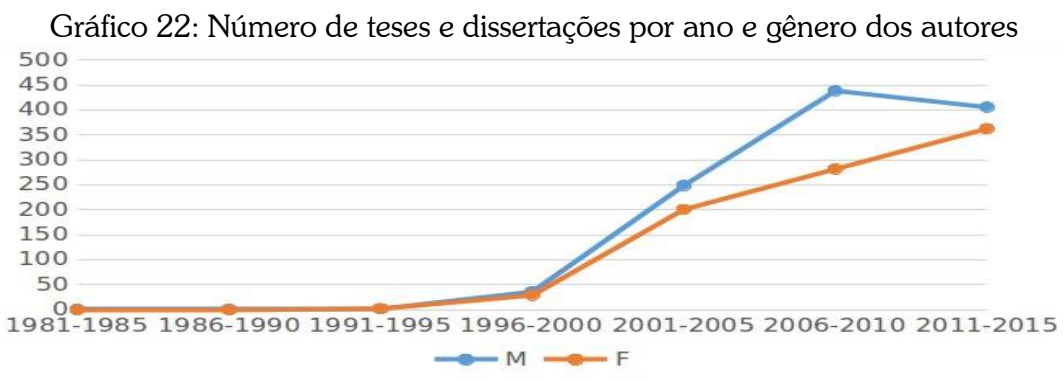

Fonte: Elaboração própria

\section{Conclusão}

Com o objetivo de gerar indicadores desagregados por gênero relativos à pesquisa no campo da tecnologia da informação no Brasil, este trabalho mapeou o espaço e a natureza da participação feminina, sob duas perspectivas: a presença de mulheres nos grupos de pesquisa ativos do Diretório dos Grupos de Pesquisa do $\mathrm{CNPq} e$ a produção científica de teses $e$ dissertações. Os resultados foram sistematizados na forma de indicadores que apontaram a concentração de mulheres em áreas de conhecimento historicamente associadas à feminização persistente, além de sugerirem a ocorrência de barreiras à ascensão hierárquica de mulheres a posições de liderança na pesquisa.

O registro do primeiro grupo de pesquisa em tecnologia da informação no Brasil data de década de 1970, ao passo que a primeira dissertação de mestrado foi defendida em 1981. Constatou-se a evolução exponencial do número de grupos de pesquisa, a partir do ano 2000, que foi acompanhada da sua masculinização, tanto em número de participantes, quanto em número de líderes. Os homens são maioria entre os participantes de todas as categorias nos grupos de pesquisa, com exceção dos estudantes egressos e dos técnicos, perfis em que as mulheres predominam. Adicionalmente, foi verificada discrepância significativa entre o grau de titulação mais alto das mulheres $e$ homens que exercem a função de técnicos nos grupos. Enquanto 
a maior parte das técnicas têm título de pós-graduação stricto sensu, a maioria dos técnicos tem apenas o ensino médio. Estes resultados indicam que uma quantidade não desprezível de mulheres com qualificação compatível com a função de pesquisadora está cadastrada como técnica, tarefa associada às atividades de apoio e rotinas operacionais, enquanto o mesmo não ocorre entre os homens.

A associação do trabalho feminino na tecnologia da informação à prestação de serviços de caráter técnico e/ou extensionista também foi confirmada pela análise da distribuição de bolsas de produtividade entre os líderes dos grupos. Em termos absolutos, os homens detêm a maior parte das bolsas e em termos comparativos, detêm também a maior parte das bolsas de produtividade em pesquisa. A presença feminina é superior apenas entre as bolsistas de produtividade em apoio técnico, desenvolvimento tecnológico e extensão, dado que revela sua subrepresentação entre o que é considerado uma elite de pesquisadores entre os pares da sua comunidade científica.

As evidências de segregação vertical são reforçadas pela constatação de que a liderança masculina predomina nos grupos da maior parte das instituições e que o número de participantes do gênero feminino é maior nos grupos em que a liderança é exercida por uma mulher. Dentre a vinte e três instituições que contam com pelo menos três grupos de pesquisa ativos no DGP$\mathrm{CNPq}$, há sessenta e quatro homens na posição de liderança, em contraposição a trinta e nove mulheres Ao mesmo tempo, a ocorrência de liderança mista - primeiro e segundo líder de gêneros distintos - é rara, sendo um pouco maior nos grupos em que o primeiro líder é mulher. Na produção científica de teses e dissertações, foi verificado que o número de autores $e$ orientadores é superior entre os homens, embora haja uma aparente tendência de crescimento de teses e dissertações de autoria feminina, a partir de 2010. Mesmo assim, tanto homens quanto mulheres ainda são majoritariamente orientados por homens. 
A distribuição dos grupos segundo áreas de conhecimento $e$ subáreas indicam que este seja um campo multidisciplinar, com predomínio das subáreas de Computação e Administração, sugerindo que uma parte significativa da pesquisa brasileira em tecnologia da informação têm caráter aplicado e orientação econômica. A análise dos percentuais de participação de homens $e$ mulheres nos grupos das diferentes áreas e subáreas de conhecimento revela fortes indícios de segregação horizontal ou temática, reforçando estereótipos que associam o trabalho feminino ao cuidado $e$ o trabalho masculino à orientação para resultados. Os homens predominam nas Engenharias e nas duas áreas que detêm o maior número de grupos de pesquisa, Computação e Administração, em que $73 \%$ e $55 \%$ dos participantes são homens, respectivamente. Por sua vez, a participação feminina é majoritária na Educação, na Ciência da Informação e na Enfermagem, nesta última representando $86 \%$ das participantes. Mesmo em áreas de feminização persistente, há predomínio da liderança masculina, a exemplo da área de Educação, onde as mulheres são a maioria dos participantes $(60 \%)$, mas a minoria entre os líderes (48\%), contabilizados primeiros e segundos lideres.

À guisa de conclusão, reconhecemos que os resultados obtidos são passíveis de revisões e atualizações, constituindo-se em uma primeira aproximação à temática focalizada no presente artigo. Até o presente momento, os resultados obtidos confirmam o argumento de Yannoulas (2011:228) de que as estatísticas "pretensamente objetivas não se limitam a registrar dados neutros e possuem a marca dos estereótipos e conceituações dadas em uma época e cultura". Os resultados aqui apresentados confirmam hipóteses de segregação horizontal e vertical de mulheres na pesquisa em tecnologia da informação $e$ sugerem a realização de estudos empíricos que possam explorar as razões subjacentes aos indicadores obtidos.

Entre os tópicos desta agenda de investigação, destacamos a necessidade de averiguação dos mecanismos que perpetuam a associação do trabalho feminino com a dimensão "técnica" da 
tecnologia da informação, em detrimento da pesquisa científica, expressa no grande número de mulheres cadastradas como técnicas dos grupos, a despeito de sua titulação e no pequeno número de mulheres contempladas com bolsas de produtividade em pesquisa, em contraponto ao número de bolsistas de produtividade em apoio técnico, desenvolvimento tecnológico e extensão. De igual importância é a avaliação das razões de concentração de mulheres em áreas historicamente feminizadas e a sua presença lacunar nos grupos das áreas mais representativas (e rentáveis) da pesquisa em tecnologia da informação. No limite, espera-se que o mapeamento retratado pelos indicadores, somado aos diagnósticos de suas razões, futuramente possam subsidiar propostas de políticas públicas, além de desenhos de programas $e$ projetos institucionais voltados para a promoção da equidade de gênero tecnologia da informação.

\section{Referências bibliográficas}

AmARAL, Marília Abrahão et alii. Investigando questões de gênero em um curso da área de Computação. Revista Estudos Feministas, Florianópolis, v. 25, n. 2, p. 857-874, Aug. 2017.

ARRUDA, Denis et alii. Brazilian computer science research: gender and regional distributions. Scientometrics, v. 79, n. 3, jun. 2009, pp. 651665 [http://link.springer.com/10.1007/s11192-007-1944-0 - acesso em 12 mar. 2018].

AUSTRALIAN-Computer-Society. Australian ICT statistical compendium. Sydney, Australian Computer Society Inc, 2012.

AzEVEDO, Nara; FerREIRA, Luiz Otávio. Modernização, políticas públicas e sistema de gênero no Brasil: educação e profissionalização feminina entre as décadas de 1920 e 1940. Cadernos Pagu, n.27, 2006, pp.213-254.

BELGORODSKIY Alexander et alii. The gender pay gap in the ICT labour market: comparative experiences from the UK and New Zealand. New Technology, Work and Employment, v. 27(2), 2012, pp.106-119.

BEYER, Sylvia. Why are women underrepresented in computer science? Gender differences in stereotypes, self-efficacy, values, and interests 
and predictors of future CS course taking and grades, Computer Science Education, v. 24, 2014, pp. 153-192.

BOHR, Bärbel. Gender codes: why women are leaving computing. The Information Society, v. 29(4), 2013, pp.252-253.

BRASIL. Decreto no 8.727, de 28 de abril de 2016. [http://www.planalto.gov.br/ccivil_03/_ato20152018/2016/decreto/D8727.htm - acesso em 27 fev 2018], 2016a.

BRASIL. Diretório dos Grupos de Pesquisa no Brasil (DGP). Glossário. [http:/lattes.cnpq.br/web/dgp/glossario/ - acesso em: $27 \mathrm{dez} 2016]$, 2016b.

BUTLER, Judith. Problemas de gênero: feminismo e subversão da identidade. Tradução de Renato Aguiar. Rio de janeiro: Civilização Brasileira, 2003

CALAS, Marta B.; SMIRCICH, Linda. Engendering the organizational: organization studies and feminist theorizing. In: ADLER, Paul et alii (Eds.). The Oxford Handbook of Sociology, Social Theory and Organization Studies: contemporary currents, 2014, pp. 605-659.

CaPuto, Carlo; ReQuena, Jaime; VARGAS, Domingo. Life sciences research in Venezuela. Scientometrics, v. 90(3), 2012, pp. 781-805.

CHERYAN, Sapna et alii. Ambient belonging: how stereotypical cues impact gender participation in computer science. Journal of Personality and Social Psychology, v. 97(6), dez. 2009, pp. 10451060.

CHERYAN, Sapna et alii. Do female and male role models who embody STEM stereotypes hinder women's anticipated success in STEM? Social Psychological and Personality Science, v. 2(6), nov. 2011, pp. 656-664.

COHOON, Joanne McGrath; ASPRAY, William. A critical review of the research on women's participation in postsecondary computing education. In: COHOON, Joanne McGrath; ASPRAY, William (Eds), Women and information technology. Cambridge - Massachusetts, MIT Press, 2006, pp. 137-180.

CowAN, Ruth Schwartz. The 'industrial revolution' in the home: household technology and social change in the 20th century. Technology and Culture, v. 17, n. 1, jan. 1976, p. 1 
[http://www.jstor.org/stable/3103251?origin=crossref - acesso em 12 mar. 2018].

CUNDIFF, Jessica L. et alii. Do gender-science stereotypes predict science identification and science career aspirations among undergraduate science majors? Social Psycholy of Education. v. 16, 2013, pp.541.

DAUTZENBERG, Kirsti. Gender differences of business owners in technology-based firms. International Journal of Gender and Entrepreneurship, v. 4, n. 1, mar. 2012, pp. 79-98 [http://www.emeraldinsight.com/doi/10.1108/17566261211202990 acesso em 12 mar. 2018].

DURBIN, Susan. Creating knowledge through networks: a gender perspective. Gender, Work \& Organization, v. 18, n. 1, 1 jan. 2011, pp. 90-112 [http://doi.wiley.com/10.1111/j.1468-0432.2010.00536.x - acesso em 12 mar. 2018].

ECKLUND, Elaine Howard; LINCOLN, Anne E.; TANSEY, Cassandra. Gender segregation in elite academic science. Gender \& Society, v. 26, n. 5, out. 2012, pp. 693717[http://journals.sagepub.com/doi/10.1177/0891243212451904 acesso em 12 mar. 2018].

FOX, Mary Frank; SONNERT, Gerhard; NIKIFOROVA, Irina. Programs for Undergraduate women in science and engineering: issues, problems, and solutions. Gender \& Society, v. 25(5), 2011, pp. 589-615.

Guedes, Moema de Castro; Azevedo, Nara; FerreIRA, Luiz Otávio. A produtividade científica tem sexo? Um estudo sobre bolsistas de produtividade do CNPq. Cadernos Pagu (45), Campinas, dez. 2015, pp.

367-399.

[http://www.scielo.br/scielo.php?script=sci arttext\&pid =S010483332015000200367\&lng=en\&nrm=iso - acesso em: $27 \mathrm{dez} 2016]$.

HARAWAY, Donna J. Simians, cyborgs and women: the reinvention of nature. New York, Routledge, 1991.

HARDING, Sandra. Sciences from below: Feminisms, postcolonialities, and modernities, Raleigh, Duke University Press, 2008.

HARDING, Sandra. Standpoint Theories: Productively Controversial, Hypatia, v.24(4), 2009, pp. 192-200. 
HERRING, Cedric. Does diversity pay? race, gender, and the business case for diversity. American Sociological Review, v. 74 (2), abr. 2009, pp. 208-224.

HUNTER, Alison. Locating Women in the New Zealand Computing Industry. Journal of Applied Computing and Information Technology, v. $16(1)$,

2012. [http://www.citrenz.ac.nz/jacit/JACIT1601/2012Hunter_ComputingWo men.html - acesso em: $27 \mathrm{dez} 2016]$.

KELLER, Evelyn Fox. Reflections of gender and science. New Haven - CT, Yale University Press, 1985.

Knobloch-Westerwick, Silvia; Glynn, Carroll J.; Huge, Michael. The matilda effect in science communication. Science Communication, v. 35, n. 5, out. 2013, pp. 603-625 [http://journals.sagepub.com/doi/10.1177/1075547012472684 acesso em 12 mar. 2018].

LETA, Jacqueline. As mulheres na ciência brasileira: crescimento, contrastes e um perfil de sucesso. Estudos Avançados, São Paulo-SP, v. $17, \quad$ n. 49, dez. 2003, pp. 271-284 [http://www.scielo.br/scielo.php?script =sci arttext\&pid =S010340142003000300016\&lng=pt\&tlng=pt - acesso em 12 mar. 2018].

LEWIS, Patricia. Postfeminism, femininities and organization studies: exploring a new agenda. Organization Studies, v. 35, n. 12, dez. 2014, pp.

$1845-1866$ [http://journals.sagepub.com/doi/10.1177/0170840614539315 acesso em 12 mar. 2018].

LI, Nai; KIRKUP, Gill. Gender and cultural differences in Internet use: a study of China and the UK. Computers in Education, v. 48(2), 2007, pp. 301-317.

LiMA, Michelle Pinto. As mulheres na Ciência da Computação. Revista Estudos Feministas, Florianópolis , v. 21, n. 3, p. 793816, dez. 2013.

LOCKARD, C. Brett; Wolf, Michael. Employment outlook: 2010-2020: occupational employment projections to 2020. Monthly Labor Review, jan. 2012, pp. 84-108. 
LONGINO, Helen E. Science as social knowledge: values and objectivity in scientific inquiry. Princeton, NJ, Princeton University Press, 1990.

LOPES, Marta Júlia Marques; LEAL, Sandra Maria Cezar. A feminização persistente na qualificação profissional da enfermagem brasileira. Cadernos Pagu (24), Campinas-SP, 2005, pp. 105-125.

LOPES, Maria Margaret; PISCITELli, Adriana. Revistas científicas e a constituição do campo de estudos de gênero: um olhar desde as "margens". Revista Estudos Feministas, Florianópolis-SC, v. 12, n. spe, dez. 2004, pp. 115-121 [http://www.scielo.br/scielo.php?script $=$ sci arttext\&pid $=$ S0104026X2004000300013\&lng=pt\&tlng=pt - acesso em 12 mar. 2018].

MAIA, Marcel Maggion. Limites de gênero e presença feminina nos cursos superiores brasileiros do campo da computação, Cadernos Pagu, (46), Campinas -SP, abr. 2016, pp.223-244.

Melo, Hildete Pereira de; OliveIRA, André Barbosa. A produção científica brasileira no feminino. cadernos pagu (27), Campinas-SP, Núcleo de Estudos de Gênero-Pagu/Unicamp, 2006, pp. 301-331 [http://www.scielo.br/pdf/cpa/n27/32146.pdf - acesso em 12 mar. 2018].

MERTON, Robert K. The Matthew effect in science. The reward and communication systems of science are considered. Science, New York-NY, v. 159, n. 3810, 5 jan. 1968, pp. 56-63 [http://www.ncbi.nlm.nih.gov/pubmed/5634379 - acesso em 12 mar. 2018].

Miguel, Ana de; BoIX, Montserrat. Os gêneros da rede: os ciberfeminismos. In: NATANSOHN, G. (Org.). Internet em código feminino: teorias e práticas. 2.ed. revista e ampliada. Buenos Aires: La Crujía, 2013, v.1.

MoREIRA, Maria Lígia; VelHO, Lea. Pós-graduação do Instituto Nacional de Pesquisas Espaciais numa perspectiva de gênero. cadernos pagu (35), Campinas-SP, Núcleo de Estudos de Gênero-Pagu/Unicamp, dez. 2010 , pp. 279-308 [http://www.scielo.br/scielo.php?script $=$ sci arttext\&pid $=$ S010483332010000200010\&lng=pt\&tlng=pt - acesso em 12 mar. 2018].

NATIONAL Science Foundation. Women, minorities, and persons with disabilities in science and engineering: 2007. Arlington, VA, 2013. 
NIELSEN, Mathias W. Limits to meritocracy? gender in academic recruitment and promotion processes. Science and Public Policy, v. 43, n. 3, jun. 2016, pp. 386-399 [https://academic.oup.com/spp/articlelookup/doi/10.1093/scipol/scv052 - acesso em 12 mar. 2018].

NUNES, Marina et alii. Meninas++: uma iniciativa para fomentar a participação feminina na área de Computação. Tecnologias, $S$ ociedade e Conhecimento. Campinas, vol. 3, n. 1,Dez.2015

OSADA, Neide Mayumi; CONCEIÇÃo DA COSTA, Maria. Fazendo gênero na biologia brasileira: obstáculos e preconceitos na produção do conhecimento no projeto genoma FAPESP. Arbor, [S.l.], v. CLXXXIV, n. 733, out. 2008, pp. 863-876 [http://arbor.revistas.csic.es/index.php/arbor/article/view/230/231 acesso em 12 mar. 2018].

OzKAZANC-PAN, Banu. Postcolonial feminist analysis of high-technology entrepreneuring. International Journal of Entrepreneurial Behavior \& Research, v. 20, n. 2, mar. 2014, pp. 155-172 [http://www.emeraldinsight.com/doi/10.1108/IJEBR-12-2011-0195 acesso em 12 mar. 2018].

PAgOWSKY, Nicole; RIGBY, Miriam E. Contextualizing ourselves: The identity politics of the librarian stereotype. In: PAGOWSKY, Nicole; RIGBY, Miriam E. (Eds.), The librarian stereotype: Deconstructing perceptions and presentations of information work. Chicago - IL, The Association of College \& Research Libraries., 2014, pp. 1-37. [http://hdl.handle.net/10150/552922- acesso em: 27 dez 2016]

PANDE, Rekha. Digital divide, gender and the Indian experience in IT. In: EILEEN, M. Trauth (Ed.). Encyclopedia of gender and information technology. Hershey-PA, Idea Group Reference, 2006, pp. 191- 199.

PAz, Mônica de Sá Dantas. Entre o movimento de mulheres da/nas TIC'Se os feminismos: uma análise do grupo /MNT - Mulheres na Tecnologia. Contemporanea, Comunicação e Cultura, v. 13, n. 2, p. 329-347, 2015.

PRETORIUS, Hendrik Willem et alii. Continuing the Discourse of Women in Information Technology: A South African Perspective. Gender, Technology and Development, v. 19(3), nov. 2015, pp. 346-369. 
[http://gtd.sagepub.com/cgi/doi/10.1177/0971852415597100 acesso em: $27 \mathrm{dez} 2016$ ]

RANGA, Marina; ETZKOWITZ, Henry. Athena in the world of techne: the gender dimension of technology, innovation and entrepreneurship. Journal of technology management \& innovation, v. 5, n. 1, jun. 2010, pp.

[http://www.scielo.cl/scielo.php?script=sci_arttext\&pid=S0718-

27242010000100001\&lng=en\&nrm=iso\&tlng=en - acesso em 12 mar. 2018].

RoCHA, Bruna; FARIAS, Leidiane Alves; AlENCAR, Tamila dos Santos M. O ciberfeminismo desencantado. [Resenha de] NATANSOHN, G. (Org.). Internet em código feminino: teorias e práticas. 2.ed. revista e ampliada. Buenos Aires: La Crujía, 2013. Revista Feminismos, v.1, n.3, set.-dez. 2013.

Rodrigues, Carla. Butler e a desconstrução do gênero. Revista Estudos Feministas, Florianópolis, v. 13, n. 1, p. 179-183, Apr. 2005.

ROSSITER, Margaret W. The matthew matilda effect in science. Social Studies of Science, v. 23, n. 2, maio 1993, p. 325-341 [http://journals.sagepub.com/doi/10.1177/030631293023002004 acesso em 12 mar. 2018].

SCHIEBINGER, Londa. (Ed.) Gendered innovations in science and engineering. Stanford, Stanford University Press, 2008. 19-24.

SCOTT, Joan. Gênero: uma categoria útil de análise histórica. Educação e Realidade, Porto Alegre, v. 20, n. 2, jul./dez., 1995.

SCHWARTZ, Juliana et alii. Mulheres na informática: quais foram as pioneiras?. Cadernos Pagu, Campinas, n. 27, p. 255278, Dec. 2006.

SomBRIO, Mariana Moraes de Oliveira. Em busca pelo campo? mulheres em expedições científicas no Brasil em meados do século XX. cadernos pagu (48), Campinas-SP, Núcleo de Estudos de GêneroPagu/Unicamp, 2016

[http://www.scielo.br/scielo.php?script=sci arttext\&pid $=$ S010483332016000300301\&lng=pt\&tlng=pt - acesso em 12 mar. 2018].

TRAUTH, Eileen.M., QUESENBERRY, Jeria L.; HUANG, Haijan. A multicultural analysis of factors influencing career choice for women 
in the information technology workforce. Journal of Global Information Management, v. 16 (4), 2008, pp. 1-23.

WAJCMAN, Judy. Feminist theories of technology. Cambridge Journal of Economics, v. 34, n. 1, jan. 2010, pp. 143-152 [https://academic.oup.com/cje/article-lookup/doi/10.1093/cje/ben057 acesso em 12 mar. 2018].

WALBY, Sylvia. Is the knowledge society gendered? Gender, Work \& Organization, v. 18, n. 1, jan. 2011, pp. 1-29 [http://doi.wiley.com/10.1111/j.1468-0432.2010.00532.x - acesso em 12 mar. 2018].

WYLIE, Alison. Os que conhecem, conhecem bem: teoria do ponto de vista e arqueologia de gênero. Scientiae Studia, São Paulo, v. 15 (1), 2017, pp. 13-38.

YANNOULAS, S. Feminização ou feminilização?: apontamentos em torno de uma categoria. Temporalis, v. 11(22), 2011, pp. 271-292. 